Supporting Information for

\title{
Chemoselective Synthesis of Lenalidomide Based PROTAC Library Using Alkylation Reaction
}

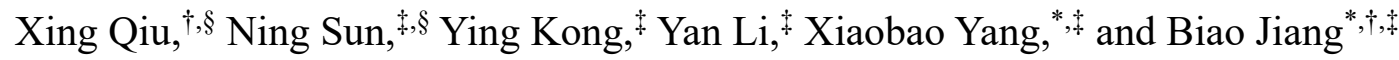

['] CAS Key Laboratory of Synthetic Chemistry of Natural Substances, Shanghai Institute of Organic Chemistry, Chinese Academy of Sciences, 345 Lingling Road, Shanghai 200032, China

$\left[{ }^{\dagger}\right.$ Shanghai Institute for Advanced Immunochemical Studies, ShanghaiTech University, Shanghai, 201210, China.

$\left[{ }^{\S}\right]$ These authors contributed equally to this work

E-mail: yangxb@shanghaitech.edu.cn, jiangbiao@shanghaitech.edu.cn.

\section{Contents of Supporting Information}

Contents:

Page

General Methods

Efficient construction of a pomalidomide ligand-based

library via microwave-mediated approach

S4-5

General procedure for the synthesis of compounds $\mathbf{8}$

S5

Characterization of products 8

S6-9

General procedure for the synthesis of compounds 9

Characterization of products 9

S9-13

General procedure for the synthesis of compounds $\mathbf{1 0}$

Characterization of products $\mathbf{1 0}$

S13-S16

General procedure for the synthesis and characterization of compounds $3 \quad$ S16-17

General procedure for the synthesis and characterization of SIAIS213110 $\quad$ S18

NMR spectra of all new compounds

S19-38 


\section{General methods.}

\section{Chemical Materials}

All chemicals were obtained from commercial suppliers (Adamas and Alfa), and used without further purification, unless otherwise indicated. $N, N$-diisopropylethylamine (DIPEA), $\quad N$-methyl-2-pyrrolidinone $\quad(\mathrm{NMP})$, dichloromethane $(\mathrm{DCM})$, acetonitrile $(\mathrm{MeCN})$ and $N, N$-dimethylformamide (DMF) were dried by a $4 \AA$ MS. Flash chromatography was carried out on silica gel (200 300 mesh). Analytical TLC was performed on Haiyang ready-to-use plates with silica gel $60\left(F_{254}\right)$. All new compounds were characterized by ${ }^{1} \mathrm{H}$ NMR, HRMS. ${ }^{1} \mathrm{H}$ NMR spectra were recorded on Bruker AVANCE III $500 \mathrm{MHZ}$ (operating at $500 \mathrm{MHz}$ for ${ }^{1} \mathrm{H}$ NMR), chemical shift were reported in ppm relative to the residual $\mathrm{d}_{6}$-DMSO $(\delta$ $\left.2.50 \mathrm{ppm}{ }^{1} \mathrm{H}\right)$ and $\mathrm{CD}_{3} \mathrm{OD}\left(\delta 3.31 \mathrm{ppm}{ }^{1} \mathrm{H}\right)$, and coupling constants $(J)$ are given in Hz. Multiplicities of signals are described as follows: s --- singlet, br. s --- broad singlet, d --- doublet, $\mathrm{t}$--- triplet, $\mathrm{m}$--- multiple. High Resolution Mass spectra were recorded on $\mathrm{AB}$ Triple 4600 spectrometer with acetonitrile and water as solvent. Compound dBET1 was synthesized as reported (G. E. Winter, D. L. Buckley, J. Paulk and J. E. Bradner, Science, 2015, 348, 1376).

Cell lines and cell culture. The multiple myeloma cell line MM1S, and the human biphenotypic B myelomonocytic cell line MV411 as well as breast cell line MDA-MB-468, were purchased from American Type Culture Collection. All these cells were cultured according to the provider's instructions and maintained at $37{ }^{\circ} \mathrm{C}$ in a humidified atmosphere containing $5 \% \mathrm{CO}_{2}$ in air.

Cell Growth Inhibition. For cell growth experiments, $4000 \sim 15000$ cells/well in $100 \mu \mathrm{L}$ were seeded into a 96-well tissue culture plate. Then compounds were diluted in the corresponding medium and then $3 \sim 5$-fold serially diluted in to each well. Cells were incubated for 3 days at $37{ }^{\circ} \mathrm{C}$ in an atmosphere of $5 \%$ $\mathrm{CO}_{2}$. Cell growth was evaluated utilizing CCK-8 assay (CK04, Dojindo Molecular Technologies, MD), incubated for $2 \sim 4 \mathrm{~h}$ in the cell culture incubator, 
and read at $450 \mathrm{~nm}$ in a Microporous plate detection system (Perkin Elmer Envision, California). The readings were normalized to the DMSO-treated cells and fitted using a nonlinear regression analysis with the GraphPad Prism 6 software to obtain the $\mathrm{IC}_{50}$ value for each compound.

Western Blotting. $0.3 \times 10^{6}$ cells $/ \mathrm{ml}$ were plated in $24-$ well plates and treated with compounds at the indicated concentrations and times. Cells were collected, washed with cold $1 \times$ PBS, and lysed in 1x SDS buffer containing protease inhibitor cocktails (\#539134, Merck). Protein in cell lysate was quantified by detergent compatible Bradford assay kit (\#23246, Thermo). Primary antibodies used in this study include BRD2 Antibody (\#5848S, Cell Signaling Technology), BRD3 Antibody (\#2088C3a, Abcam), BRD4 Antibody (\#13440S, Cell Signaling Technology), C-Myc antibody (\#5605S, Cell Signaling Technology). The Millipose Immobilon Western Chemiluminescence Substrate was used for signal development. Blots were imaged in an Amersham Imager 600 (GE Healthcare). 


\section{Efficient construction of a pomalidomide Ligand-based Library via}

microwave-mediated approach.
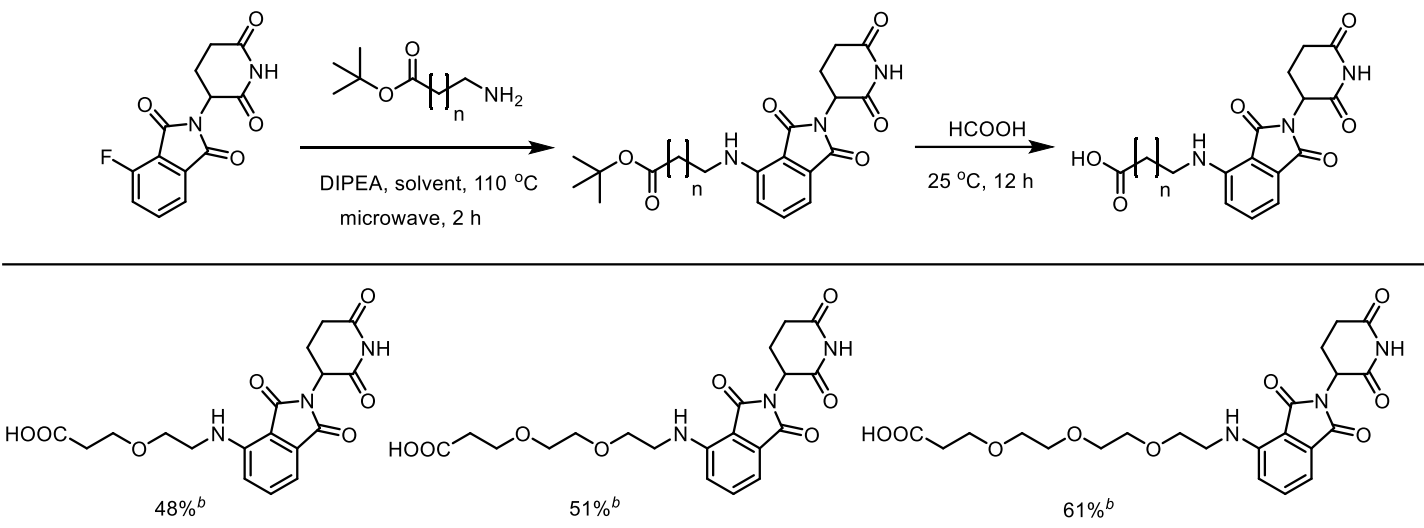<smiles>O=C(O)CCOCCOCCOCCOCCNc1cccc2c1C(=O)N(C1CCC(=O)NC1=O)C2=O</smiles>

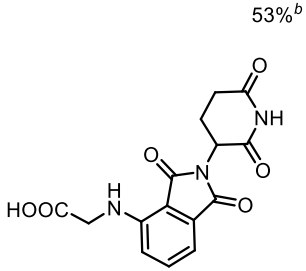

$48 \%^{\circ}$

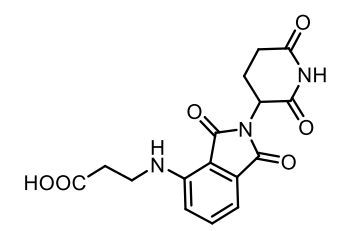

$39 \%^{\mathrm{c}}$

$51 \%^{b}$<smiles>O=C(O)CCCNc1cccc2c1C(=O)N(C1CCC(=O)NC1=O)C2=O</smiles>

$61 \%^{\mathrm{c}}$

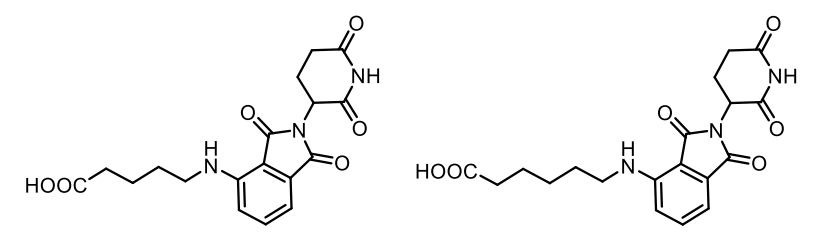

$50 \%^{\mathrm{C}}$

$61 \%^{\circ}$

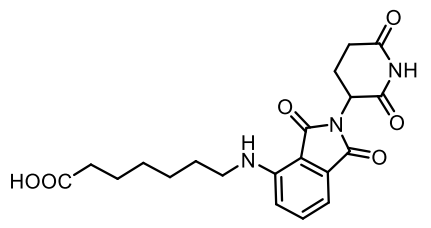

$64 \%^{\circ}$

a Isolated yield over 2 steps. ${ }^{b}$ DMF was used as solvent for the first step. ${ }^{c}$ NMP was used as solvent for the first step. 

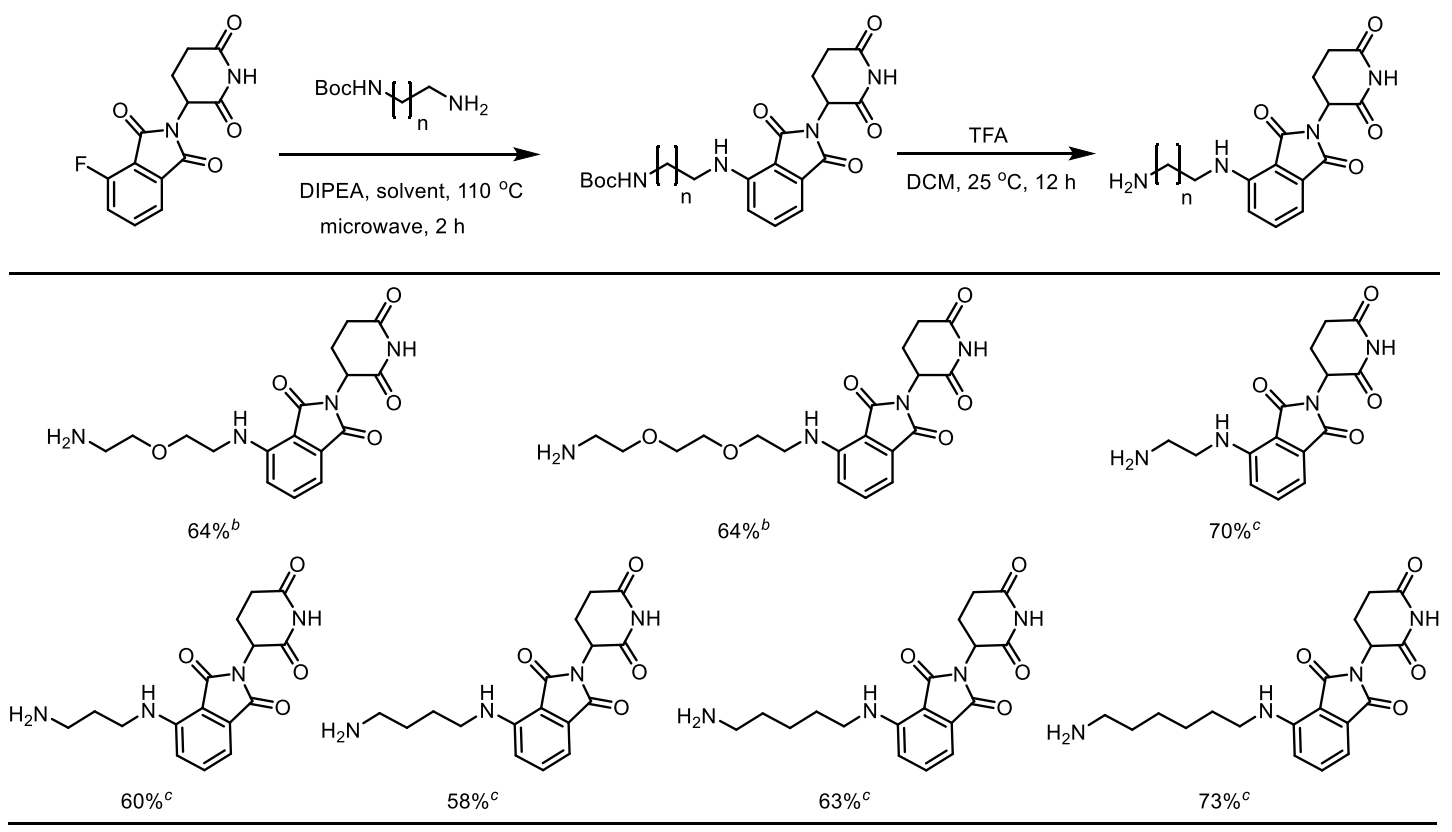

alsolated yield over 2 steps. ${ }^{b} \mathrm{DMF}$ was used as solvent for the first step. ${ }^{c} \mathrm{NMP}$ was used as solvent for the first step.

3. General procedure for the synthesis of compounds 8 .

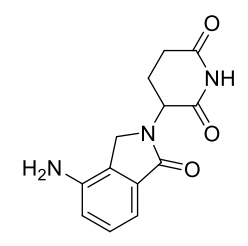

1a

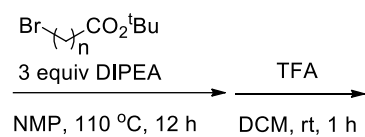

NMP, $110^{\circ} \mathrm{C}, 12 \mathrm{~h} \quad \mathrm{DCM}, \mathrm{rt}, 1 \mathrm{~h}$

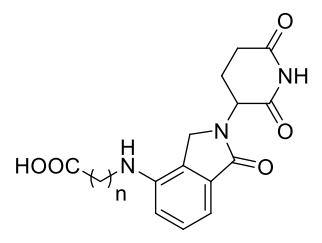

$8 a-8 f$

To a stirred solution of 3-(4-amino-1-oxoisoindolin-2-yl)piperidine-2,6-dione (1.0 equiv) in NMP (5 mL) were added DIPEA (3.0 equiv) and linkers (5, 1.2 equiv). Then the resulting mixture was stirred at $110^{\circ} \mathrm{C}$ for $12 \mathrm{~h}$. When the reaction was complete, the crude mixture was purified by $\mathrm{C} 18$ (eluent: with 10\%-100\% (v1:v2) acetonitrile in water) to afford intermediate tert-butyl esters. To a mixture of intermediate tert-butyl esters in DCM (4 mL), TFA $(2 \mathrm{~mL})$ was added and stirred at $25{ }^{\circ} \mathrm{C}$ for $1 \mathrm{~h}$. When the reaction was complete, the crude mixture was evaporated under the reduced pressure, the residue was purified by freeze-drying to obtain target compounds (8). 


\section{Characterization data of products 8 .}<smiles>O=C(O)CNc1cccc2c1CN(C1CCC(=O)NC1=O)C2=O</smiles>

(2-(2,6-dioxopiperidin-3-yl)-1-oxoisoindolin-4-yl)glycine (8a). The crude product was purified by $\mathrm{C} 18$ (eluent: with 10\%-100\% (v1:v2) acetonitrile in water). (yellow solid, $1.0 \mathrm{~g}, 48 \%){ }^{1} \mathrm{H}$ NMR (500 MHz, DMSO) $\delta 11.01$ (s, 1H), 7.28 (t, $J=7.7 \mathrm{~Hz}$, $1 \mathrm{H}), 6.98(\mathrm{~d}, J=7.3 \mathrm{~Hz}, 1 \mathrm{H}), 6.66(\mathrm{~d}, J=8.0 \mathrm{~Hz}, 1 \mathrm{H}), 5.94(\mathrm{~s}, 1 \mathrm{H}), 5.12(\mathrm{dd}, J=13.3$, $5.1 \mathrm{~Hz}, 1 \mathrm{H}), 4.26(\mathrm{~d}, J=17.0 \mathrm{~Hz}, 1 \mathrm{H}), 4.16(\mathrm{~d}, J=17.0 \mathrm{~Hz}, 1 \mathrm{H}), 3.92(\mathrm{~s}, 2 \mathrm{H}), 2.98-$ $2.85(\mathrm{~m}, 1 \mathrm{H}), 2.62(\mathrm{~d}, J=17.3 \mathrm{~Hz}, 1 \mathrm{H}), 2.39-2.26(\mathrm{~m}, 1 \mathrm{H}), 2.08-1.99(\mathrm{~m}, 1 \mathrm{H}) ;{ }^{13} \mathrm{C}$ NMR (126 MHz, DMSO) $\delta 172.32,171.74,170.63,168.15,142.62,131.52,128.54$, 126.02, 111.61, 110.20, 50.94, 45.04, 43.78, 30.65, 22.15. HRMS (ESI) m/z: calcd for $\mathrm{C}_{15} \mathrm{H}_{16} \mathrm{~N}_{3} \mathrm{O}_{5}^{+}[\mathrm{M}+\mathrm{H}]^{+}, 318.1084$; found, 318.1098.<smiles>O=C(O)CCNc1cccc2c1CN(C1CCC(=O)NC1=O)C2=O</smiles>

3-((2-(2,6-dioxopiperidin-3-yl)-1-oxoisoindolin-4-yl)amino)propanoic acid (8b).

The crude product was purified by $\mathrm{C} 18$ (eluent: with 10\%-100\% (v1:v2) acetonitrile in water). (yellow solid, $1.0 \mathrm{~g}, 48 \%){ }^{1} \mathrm{H}$ NMR (500 MHz, DMSO) $\delta 11.00$ (s, 1H), $7.31(\mathrm{t}, J=7.7 \mathrm{~Hz}, 1 \mathrm{H}), 6.96(\mathrm{~d}, J=7.4 \mathrm{~Hz}, 1 \mathrm{H}), 6.79$ (d, $J=8.0 \mathrm{~Hz}, 1 \mathrm{H}), 5.11(\mathrm{dd}, J$ $=13.3,5.1 \mathrm{~Hz}, 1 \mathrm{H}), 4.21(\mathrm{~d}, J=17.0 \mathrm{~Hz}, 1 \mathrm{H}), 4.12(\mathrm{~d}, J=17.0 \mathrm{~Hz}, 1 \mathrm{H}), 4.08(\mathrm{~s}, 1 \mathrm{H})$, $3.37(\mathrm{t}, J=6.9 \mathrm{~Hz}, 2 \mathrm{H}), 2.98-2.86(\mathrm{~m}, 1 \mathrm{H}), 2.65-2.57(\mathrm{~m}, 1 \mathrm{H}), 2.54(\mathrm{t}, J=6.9 \mathrm{~Hz}$, 2H), $2.33-2.26(\mathrm{~m}, 1 \mathrm{H}), 2.07-1.99(\mathrm{~m}, 1 \mathrm{H}) ;{ }^{13} \mathrm{C} \mathrm{NMR}(126 \mathrm{MHz}, \mathrm{DMSO}) \delta 173.52$, $173.33,171.67,169.30,143.77,132.58,129.74,127.22,112.42,110.96,51.97,46.13$, 
39.22, 34.02, 31.72, 23.27. HRMS (ESI) m/z: calcd for $\mathrm{C}_{16} \mathrm{H}_{18} \mathrm{~N}_{3} \mathrm{O}_{5}{ }^{+}[\mathrm{M}+\mathrm{H}]^{+}$, 332.1241; found, 332.1259 .<smiles>O=C(O)CCCNc1cccc2c1CN(C1CCC(=O)NC1=O)C2=O</smiles>

4-((2-(2,6-dioxopiperidin-3-yl)-1-oxoisoindolin-4-yl)amino)butanoic acid (8c). The crude product was purified by $\mathrm{C} 18$ (eluent: with 10\%-100\% (v1:v2) acetonitrile in water). (yellow solid, $215 \mathrm{mg}, 62 \%){ }^{1} \mathrm{H}$ NMR (500 MHz, DMSO) $\delta 11.01(\mathrm{~s}, 1 \mathrm{H})$, $7.28(\mathrm{t}, J=7.7 \mathrm{~Hz}, 1 \mathrm{H}), 6.93(\mathrm{~d}, J=7.3 \mathrm{~Hz}, 1 \mathrm{H}), 6.77(\mathrm{~d}, J=8.0 \mathrm{~Hz}, 1 \mathrm{H}), 5.11(\mathrm{dd}, J$ $=13.3,5.1 \mathrm{~Hz}, 1 \mathrm{H}), 4.23(\mathrm{~d}, J=17.0 \mathrm{~Hz}, 1 \mathrm{H}), 4.13(\mathrm{~d}, J=17.0 \mathrm{~Hz}, 1 \mathrm{H}), 4.01(\mathrm{~s}, 1 \mathrm{H})$, $3.14(\mathrm{t}, J=7.0 \mathrm{~Hz}, 2 \mathrm{H}), 2.98-2.86(\mathrm{~m}, 1 \mathrm{H}), 2.66-2.58(\mathrm{~d}, J=17.6 \mathrm{~Hz}, 1 \mathrm{H}), 2.34(\mathrm{t}$, $J=7.3 \mathrm{~Hz}, 2 \mathrm{H}), 2.32-2.24(\mathrm{~m}, 1 \mathrm{H}), 2.08-1.98(\mathrm{~m}, 1 \mathrm{H}), 1.85-1.75(\mathrm{~m}, 2 \mathrm{H}) ;{ }^{13} \mathrm{C}$ NMR (126 MHz, DMSO) $\delta 174.92,173.40,171.73,169.35,144.07,132.54,129.71$, 127.03, 112.22, 110.54, 51.96, 46.18, 42.47, 31.71, 31.64, 24.34, 23.29. HRMS (ESI) $\mathrm{m} / \mathrm{z}$ : calcd for $\mathrm{C}_{17} \mathrm{H}_{20} \mathrm{~N}_{3} \mathrm{O}_{5}{ }^{+}[\mathrm{M}+\mathrm{H}]^{+}, 346.1379$; found, 346.1370 .<smiles>O=C(O)CCCCNc1cccc2c1CN(C1CCC(=O)NC1=O)C2=O</smiles>

5-((2-(2,6-dioxopiperidin-3-yl)-1-oxoisoindolin-4-yl)amino)pentanoic acid (8d). The crude product was purified by $\mathrm{C} 18$ (eluent: with 10\%-100\% (v1:v2) acetonitrile in water). (yellow solid, $215 \mathrm{mg}, 60 \%){ }^{1} \mathrm{H}$ NMR (500 MHz, DMSO) $\delta 11.00(\mathrm{~s}, 1 \mathrm{H})$, $7.28(\mathrm{t}, J=7.7 \mathrm{~Hz}, 1 \mathrm{H}), 6.92(\mathrm{t}, J=10.9 \mathrm{~Hz}, 1 \mathrm{H}), 6.76(\mathrm{~d}, J=8.0 \mathrm{~Hz}, 1 \mathrm{H}), 5.11(\mathrm{dd}, J$ $=13.3,5.1 \mathrm{~Hz}, 1 \mathrm{H}), 5.07(\mathrm{~s}, 1 \mathrm{H}), 4.23(\mathrm{~d}, J=17.2 \mathrm{~Hz}, 1 \mathrm{H}), 4.13(\mathrm{~d}, J=17.1 \mathrm{~Hz}, 1 \mathrm{H})$, $3.13(\mathrm{~d}, J=6.4 \mathrm{~Hz}, 2 \mathrm{H}), 2.97-2.87(\mathrm{~m}, 1 \mathrm{H}), 2.61(\mathrm{~d}, J=16.7 \mathrm{~Hz}, 1 \mathrm{H}), 2.38-2.21$ $(\mathrm{m}, 3 \mathrm{H}), 2.06-1.98(\mathrm{~m}, 1 \mathrm{H}), 1.67-1.55(\mathrm{~m}, 4 \mathrm{H}) ;{ }^{13} \mathrm{C} \mathrm{NMR}(126 \mathrm{MHz}, \mathrm{DMSO}) \delta$ 
$174.98,173.43,171.75,169.38,144.10,132.51,129.72,126.97,112.30,110.49$, 51.94, 46.19, 42.88, 33.92, 31.70, 28.41, 22.65, 21.25. HRMS (ESI) m/z: calcd for $\mathrm{C}_{18} \mathrm{H}_{22} \mathrm{~N}_{3} \mathrm{O}_{5}^{+}[\mathrm{M}+\mathrm{H}]^{+}, 360.1554$; found, 360.1543 .

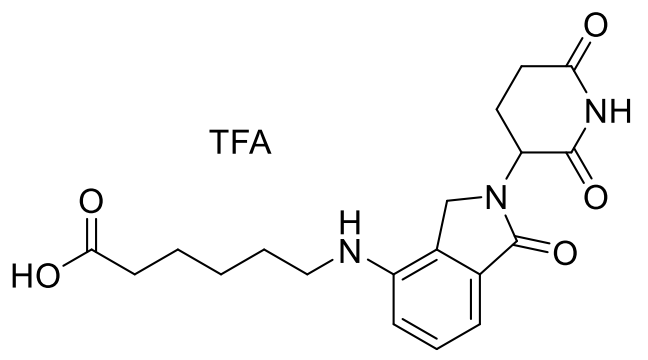

\section{N-(5-carboxypentyl)-2-(2,6-dioxopiperidin-3-yl)-1-oxoisoindolin-4-aminium}

2,2,2-trifluoroacetate (8e). (yellow solid, $268 \mathrm{mg}, 72 \%){ }^{1} \mathrm{H}$ NMR (500 MHz, DMSO) $\delta 11.01(\mathrm{~s}, 1 \mathrm{H}), 7.29$ (t, $J=7.7 \mathrm{~Hz}, 1 \mathrm{H}), 6.94(\mathrm{~d}, J=7.4 \mathrm{~Hz}, 1 \mathrm{H}), 6.76(\mathrm{~d}, J=8.0 \mathrm{~Hz}$, $1 \mathrm{H}), 5.11(\mathrm{dd}, J=13.3,5.1 \mathrm{~Hz}, 1 \mathrm{H}), 4.24(\mathrm{~d}, J=17.0 \mathrm{~Hz}, 1 \mathrm{H}), 4.14(\mathrm{~d}, J=17.0 \mathrm{~Hz}$, $1 \mathrm{H}), 4.05(\mathrm{~s}, 1 \mathrm{H}), 3.12(\mathrm{t}, J=7.0 \mathrm{~Hz}, 2 \mathrm{H}), 2.98-2.87(\mathrm{~m}, 1 \mathrm{H}), 2.66-2.58(\mathrm{~m}, 1 \mathrm{H})$, $2.35-2.25(\mathrm{~m}, 1 \mathrm{H}), 2.22(\mathrm{t}, J=7.0 \mathrm{~Hz}, 2 \mathrm{H}), 2.07-2.00(\mathrm{~m}, 1 \mathrm{H}), 1.63-1.50(\mathrm{~m}, 4 \mathrm{H})$, 1.43 - $1.37(\mathrm{~m}, 2 \mathrm{H}) ;{ }^{13} \mathrm{C}$ NMR (126 MHz, DMSO) $\delta 174.93,173.38,171.73,169.32$, $158.79(\mathrm{q}, J=38.0 \mathrm{~Hz}), 143.99,132.56,129.71,127.11,115.66(\mathrm{q}, J=289.2 \mathrm{~Hz})$, $112.49,110.67,51.95,46.18,43.21,34.13,31.71,28.68,26.66,24.83,23.30$. HRMS (ESI) $\mathrm{m} / \mathrm{z}$ : calcd for $\mathrm{C}_{19} \mathrm{H}_{24} \mathrm{~N}_{3} \mathrm{O}_{5}{ }^{+}[\mathrm{M}+\mathrm{H}]^{+}, 374.1710$; found, 374.1720.

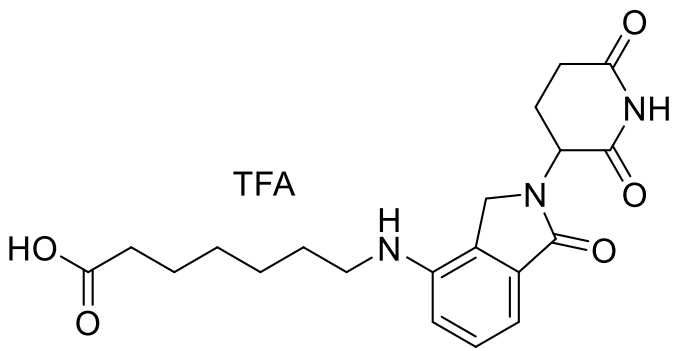

\section{N-(6-carboxyhexyl)-2-(2,6-dioxopiperidin-3-yl)-1-oxoisoindolin-4-aminium}

2,2,2-trifluoroacetate (8f). (yellow solid, $252 \mathrm{mg}, 65 \%$ ) ${ }^{1} \mathrm{H}$ NMR (500 MHz, DMSO) $\delta 11.00(\mathrm{~s}, 1 \mathrm{H}), 7.28(\mathrm{t}, J=7.7 \mathrm{~Hz}, 1 \mathrm{H}), 6.93(\mathrm{~d}, J=7.3 \mathrm{~Hz}, 1 \mathrm{H}), 6.75(\mathrm{~d}, J=8.0 \mathrm{~Hz}$, 1H), $5.11(\mathrm{dd}, J=13.2,5.0 \mathrm{~Hz}, 1 \mathrm{H}), 4.23(\mathrm{~d}, J=17.0 \mathrm{~Hz}, 1 \mathrm{H}), 4.13(\mathrm{~d}, J=17.0 \mathrm{~Hz}$, $1 \mathrm{H}), 3.11(\mathrm{t}, J=7.0 \mathrm{~Hz}, 2 \mathrm{H}), 2.98-2.84(\mathrm{~m}, 1 \mathrm{H}), 2.67-2.57(\mathrm{~m}, 1 \mathrm{H}), 2.35-2.25(\mathrm{~m}$, $1 \mathrm{H}), 2.20(\mathrm{t}, J=7.3 \mathrm{~Hz}, 2 \mathrm{H}), 2.07-1.99(\mathrm{~m}, 1 \mathrm{H}), 1.63-1.46(\mathrm{~m}, 4 \mathrm{H}), 1.42-1.27(\mathrm{~m}$, 
$4 \mathrm{H}) ;{ }^{13} \mathrm{C}$ NMR $(126 \mathrm{MHz}, \mathrm{DMSO}) \delta 174.97,173.38,171.73,169.31,158.81$ (q, $J=$ $38.0 \mathrm{~Hz}), 143.92,132.56,129.71,127.18,115.65$ (q, $J=289.2 \mathrm{~Hz}), 112.58,110.75$, 51.96, 46.19, 43.34, 34.10, 31.71, 28.87, 28.78, 26.81, 24.94, 23.29. HRMS (ESI) m/z: calcd for $\mathrm{C}_{20} \mathrm{H}_{26} \mathrm{~N}_{3} \mathrm{O}_{5}^{+}[\mathrm{M}+\mathrm{H}]^{+}, 388.1867$; found, 388.1876.

\section{General procedure for the synthesis of compounds 9.}<smiles>Nc1cccc2c1CN(C1CCC(=O)NC1=O)C2=O</smiles>

1a

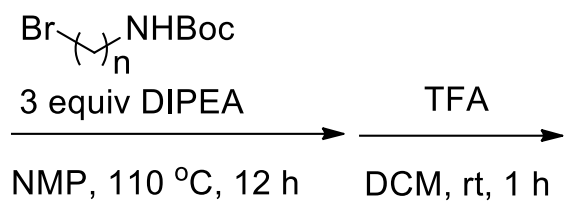

NMP $, 110^{\circ} \mathrm{C}, 12 \mathrm{~h} \quad \mathrm{DCM}, \mathrm{rt}, 1 \mathrm{~h}$<smiles>NCNc1cccc2c1CN(C1CCC(=O)NC1=O)C2=O</smiles>

9a-9f

To a stirred solution of 3-(4-amino-1-oxoisoindolin-2-yl)piperidine-2,6-dione (1.0 equiv) in NMP (5 mL) were added DIPEA (3.0 equiv) and linkers (1.2 equiv). Then the resulting mixture was stirred at $110^{\circ} \mathrm{C}$ for $12 \mathrm{~h}$. When the reaction was complete, the crude mixture was purified by $\mathrm{C} 18$ (eluent: with 10\% - 100\%(v1:v2)acetonitrile in water) to afford intermediate tert-butyl esters. To a mixture of intermediate tert-butyl esters in DCM (4 mL), TFA (2 mL) was added and stirred for $1 \mathrm{~h}$ at $25{ }^{\circ} \mathrm{C}$. When the reaction was complete, the crude mixture was evaporated under the reduced pressure, the residue was purified by freeze-drying to afford target compounds (9).

\section{Characterization data of products 9.}<smiles>NCCCNc1cccc2c1CN(C1CCC(=O)NC1=O)C2=O</smiles> 
3-(4-((3-aminopropyl)amino)-1-oxoisoindolin-2-yl)piperidine-2,6-dione (9a). The crude product was purified by C18 (eluent: with 10\%-100\% (v1:v2) acetonitrile in water). (yellow liquid, $159 \mathrm{mg}, 50 \%){ }^{1} \mathrm{H}$ NMR (500 MHz, DMSO) $\delta 11.01(\mathrm{~s}, 1 \mathrm{H})$, 7.93 (s, 1H), $7.71(\mathrm{~s}, 2 \mathrm{H}), 7.31$ (t, $J=7.7 \mathrm{~Hz}, 1 \mathrm{H}), 6.96$ (d, $J=7.4 \mathrm{~Hz}, 1 \mathrm{H}), 6.79$ (d, $J$ $=8.1 \mathrm{~Hz}, 1 \mathrm{H}), 5.12(\mathrm{dd}, J=13.2,5.1 \mathrm{~Hz}, 1 \mathrm{H}), 4.21(\mathrm{~d}, J=17.0 \mathrm{~Hz}, 1 \mathrm{H}), 4.12(\mathrm{~d}, J=$ $17.0 \mathrm{~Hz}, 1 \mathrm{H}), 3.22(\mathrm{t}, J=6.4 \mathrm{~Hz}, 2 \mathrm{H}), 2.98-2.92(\mathrm{~m}, 1 \mathrm{H}), 2.92-2.87(\mathrm{~m}, 2 \mathrm{H}), 2.67$ - $2.58(\mathrm{~m}, 1 \mathrm{H}), 2.34-2.23(\mathrm{~m}, 1 \mathrm{H}), 2.08-2.00(\mathrm{~m}, 1 \mathrm{H}), 1.88-1.79(\mathrm{~m}, 2 \mathrm{H}) ;{ }^{13} \mathrm{C}$ NMR (126 MHz, DMSO) $\delta 171.29,169.46,166.82,139.25,130.83,127.73,126.85$, 113.26, 111.33, 49.93, 44.37, 39.27, 34.99, 29.53, 24.01, 21.09. HRMS (ESI) m/z: calcd for $\mathrm{C}_{16} \mathrm{H}_{21} \mathrm{~N}_{4} \mathrm{O}_{3}{ }^{+}[\mathrm{M}+\mathrm{H}]^{+}, 317.1608$; found, 317.1616 .

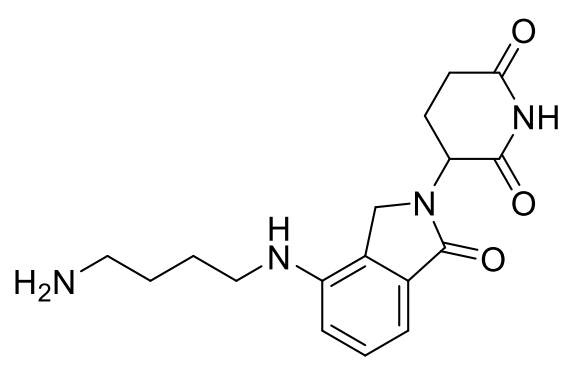

3-(4-((4-aminobutyl)amino)-1-oxoisoindolin-2-yl)piperidine-2,6-dione (9b). The crude product was purified by C18 (eluent: with 10\%-100\% (v1:v2) acetonitrile in water). (yellow liquid, $60 \mathrm{mg}, 18 \%){ }^{1} \mathrm{H}$ NMR (500 MHz, DMSO) $\delta 11.01(\mathrm{~s}, 1 \mathrm{H})$, 7.87 (s, 1H), 7.69 (s, 2H), 7.29 (t, $J=7.7 \mathrm{~Hz}, 1 \mathrm{H}), 6.94$ (d, J=7.3 Hz, 1H), 6.77 (d, $J$ $=8.0 \mathrm{~Hz}, 1 \mathrm{H}), 5.13(\mathrm{dd}, J=13.3,5.1 \mathrm{~Hz}, 1 \mathrm{H}), 4.22(\mathrm{~d}, J=17.1 \mathrm{~Hz}, 1 \mathrm{H}), 4.11(\mathrm{~d}, J=$ $17.1 \mathrm{~Hz}, 1 \mathrm{H}), 3.25-3.12(\mathrm{~m}, 2 \mathrm{H}), 3.00-2.88(\mathrm{~m}, 1 \mathrm{H}), 2.88-2.75(\mathrm{~m}, 2 \mathrm{H}), 2.67-$ $2.57(\mathrm{~m}, 1 \mathrm{H}), 2.33-2.22(\mathrm{~m}, 1 \mathrm{H}), 2.10-1.98(\mathrm{~m}, 1 \mathrm{H}), 1.66-1.50(\mathrm{~m}, 4 \mathrm{H}) ;{ }^{13} \mathrm{C}$ NMR (126 MHz, DMSO) $\delta 173.40,171.70,169.20,143.23,132.68,129.76,127.64$, 113.37, 111.47, 51.98, 46.33, 42.92, 38.99, 31.70, 25.62, 25.12, 23.30. HRMS (ESI) $\mathrm{m} / \mathrm{z}$ : calcd for $\mathrm{C}_{17} \mathrm{H}_{23} \mathrm{~N}_{4} \mathrm{O}_{3}{ }^{+}[\mathrm{M}+\mathrm{H}]^{+}, 331.1765$; found, 331.1769 .

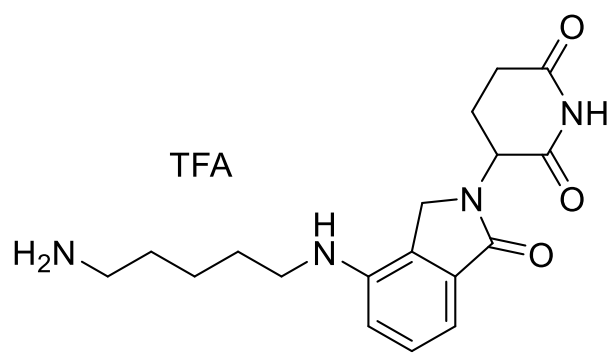




\section{5-((2-(2,6-dioxopiperidin-3-yl)-1-oxoisoindolin-4-yl)amino)pentan-1-aminium}

2,2,2-trifluoroacetate (9c). (yellow liquid, $234 \mathrm{mg}, 68 \%$ ) ${ }^{1} \mathrm{H}$ NMR (500 MHz, DMSO) $\delta 11.01(\mathrm{~s}, 1 \mathrm{H}), 7.69$ (bs, 3H), 7.29 (t, $J=7.7 \mathrm{~Hz}, 1 \mathrm{H}), 6.94$ (d, $J=7.1 \mathrm{~Hz}$, $1 \mathrm{H}), 6.75(\mathrm{~d}, J=8.0 \mathrm{~Hz}, 1 \mathrm{H}), 5.12(\mathrm{dd}, J=13.3,5.1 \mathrm{~Hz}, 1 \mathrm{H}), 4.23(\mathrm{~d}, J=17.1 \mathrm{~Hz}$, $1 \mathrm{H}), 4.13(\mathrm{~d}, J=17.1 \mathrm{~Hz}, 1 \mathrm{H}), 3.13(\mathrm{t}, J=7.0 \mathrm{~Hz}, 2 \mathrm{H}), 2.98-2.88(\mathrm{~m}, 1 \mathrm{H}), 2.84-$ $2.75(\mathrm{~m}, 2 \mathrm{H}), 2.67-2.57(\mathrm{~m}, 1 \mathrm{H}), 2.35-2.22(\mathrm{~m}, 1 \mathrm{H}), 2.08-1.99(\mathrm{~m}, 1 \mathrm{H}), 1.65-$ $1.51(\mathrm{~m}, 4 \mathrm{H}), 1.45-1.37(\mathrm{~m}, 2 \mathrm{H}) ;{ }^{13} \mathrm{C} \mathrm{NMR}(126 \mathrm{MHz}, \mathrm{DMSO}) \delta 173.38,171.71$, $169.34,158.95$ (q, $J=37.2 \mathrm{~Hz}), 143.88,132.56,129.70,127.18,115.90(\mathrm{q}, J=290.2$ Hz), 112.52, 110.81, 51.97, 46.18, 43.04, 39.26, 31.69, 28.30, 27.26, 23.85, 23.27. HRMS (ESI) m/z: calcd for $\mathrm{C}_{18} \mathrm{H}_{25} \mathrm{~N}_{4} \mathrm{O}_{3}{ }^{+}[\mathrm{M}+\mathrm{H}]^{+}$, 345.1921; found, 345.1939.

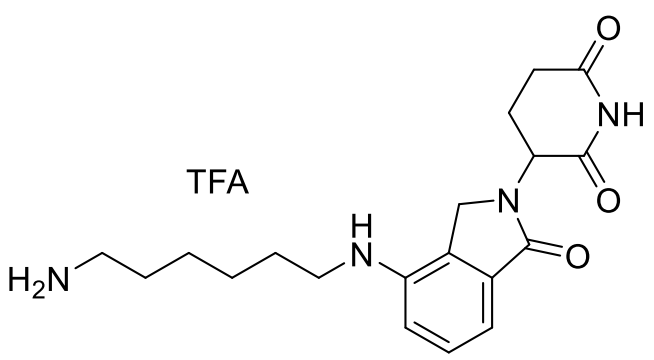

\section{6-((2-(2,6-dioxopiperidin-3-yl)-1-oxoisoindolin-4-yl)amino)hexan-1-aminium}

2,2,2-trifluoroacetate (9d). (yellow liquid, $243 \mathrm{mg}, 76 \%){ }^{1} \mathrm{H}$ NMR (500 MHz, DMSO) $\delta 11.01(\mathrm{~s}, 1 \mathrm{H}), 7.67(\mathrm{bs}, 3 \mathrm{H}), 7.29(\mathrm{t}, J=7.7 \mathrm{~Hz}, 1 \mathrm{H}), 6.93(\mathrm{~d}, J=6.9 \mathrm{~Hz}$, $1 \mathrm{H}), 6.75(\mathrm{~d}, J=7.8 \mathrm{~Hz}, 1 \mathrm{H}), 5.12(\mathrm{dd}, J=13.3,5.1 \mathrm{~Hz}, 1 \mathrm{H}), 4.23(\mathrm{~d}, J=17.1 \mathrm{~Hz}$, 1H), $4.12(\mathrm{~d}, J=17.1 \mathrm{~Hz}, 1 \mathrm{H}), 3.13(\mathrm{t}, J=7.0 \mathrm{~Hz}, 2 \mathrm{H}), 2.98-2.87(\mathrm{~m}, 1 \mathrm{H}), 2.82-$ $2.72(\mathrm{~m}, 2 \mathrm{H}), 2.67-2.57(\mathrm{~m}, 1 \mathrm{H}), 2.35-2.23(\mathrm{~m}, 1 \mathrm{H}), 2.08-2.00(\mathrm{~m}, 1 \mathrm{H}), 1.62-$ $1.49(\mathrm{~m}, 4 \mathrm{H}), 1.43-1.29(\mathrm{~m}, 4 \mathrm{H}) ;{ }^{13} \mathrm{C} \mathrm{NMR}(126 \mathrm{MHz}, \mathrm{DMSO}) \delta 173.38,171.73$, $169.35,158.92(\mathrm{q}, J=36.3 \mathrm{~Hz}), 144.05,132.55,129.68,127.06,116.18$ (q, $J=291.6$ $\mathrm{Hz}), 112.37,110.59,51.96,46.21,43.13,39.27,31.70,28.75,27.48,26.60,26.11$, 23.29. HRMS (ESI) $\mathrm{m} / \mathrm{z}$ : calcd for $\mathrm{C}_{19} \mathrm{H}_{27} \mathrm{~N}_{4} \mathrm{O}_{3}{ }^{+}[\mathrm{M}+\mathrm{H}]^{+}, 359.2078$; found, 359.2090 . 
<smiles>NCCCCCCCNc1cccc2c1CN(C1CCC(=O)NC1=O)C2=O</smiles>

\section{7-((2-(2,6-dioxopiperidin-3-yl)-1-oxoisoindolin-4-yl)amino)heptan-1-aminium}

2,2,2-trifluoroacetate (9e). (yellow liquid, $283 \mathrm{mg}, 76 \%$ ) ${ }^{1} \mathrm{H}$ NMR (500 MHz, DMSO) $\delta 11.01(\mathrm{~s}, 1 \mathrm{H}), 7.68(\mathrm{bs}, 3 \mathrm{H}), 7.29(\mathrm{t}, J=7.7 \mathrm{~Hz}, 1 \mathrm{H}), 6.93(\mathrm{t}, J=7.2 \mathrm{~Hz}$, $1 \mathrm{H}), 6.75(\mathrm{~d}, J=8.0 \mathrm{~Hz}, 1 \mathrm{H}), 5.12(\mathrm{dd}, J=13.3,5.1 \mathrm{~Hz}, 1 \mathrm{H}), 4.23(\mathrm{~d}, J=17.1 \mathrm{~Hz}$, $1 \mathrm{H}), 4.12(\mathrm{~d}, J=17.1 \mathrm{~Hz}, 1 \mathrm{H}), 3.12(\mathrm{t}, J=7.1 \mathrm{~Hz}, 2 \mathrm{H}), 2.98-2.87(\mathrm{~m}, 1 \mathrm{H}), 2.83-$ $2.72(\mathrm{~m}, 2 \mathrm{H}), 2.66-2.58(\mathrm{~m}, 1 \mathrm{H}), 2.35-2.23(\mathrm{~m}, 1 \mathrm{H}), 2.08-1.99(\mathrm{~m}, 1 \mathrm{H}), 1.62-$ $1.55(\mathrm{~m}, 2 \mathrm{H}), 1.55-1.49(\mathrm{~m}, 2 \mathrm{H}), 1.40-1.34(\mathrm{~m}, 2 \mathrm{H}), 1.34-1.29(\mathrm{~m}, 4 \mathrm{H})$; HRMS (ESI) m/z: ${ }^{13} \mathrm{C}$ NMR (126 MHz, DMSO) $\delta 173.39,171.74,169.35,158.85$ (q, $J=$ $36.4 \mathrm{~Hz}), 144.10,132.54,129.69,127.01,116.16$ (q, $J=291.6 \mathrm{~Hz}), 112.32,110.53$, $51.95,46.20,43.20,39.28,31.71,28.87,28.86,27.45,26.92,26.28,23.29$. HRMS (ESI) m/z: calcd for $\mathrm{C}_{20} \mathrm{H}_{29} \mathrm{~N}_{4} \mathrm{O}_{3}{ }^{+}[\mathrm{M}+\mathrm{H}]^{+}, 373.2234$; found, 373.2242.

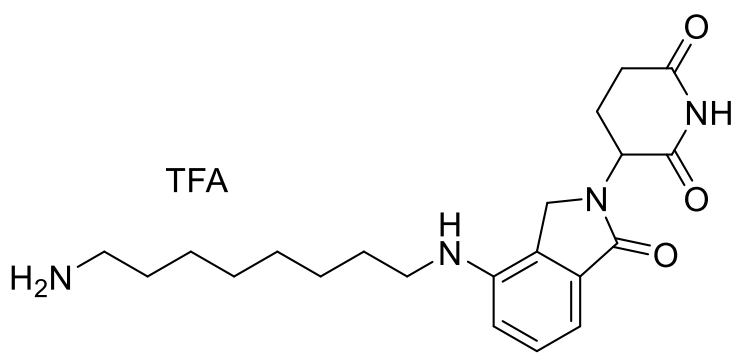

\section{8-((2-(2,6-dioxopiperidin-3-yl)-1-oxoisoindolin-4-yl)amino)octan-1-aminium}

2,2,2-trifluoroacetate (9f). (yellow liquid, $274 \mathrm{mg}, 71 \%$ ) ${ }^{1} \mathrm{H}$ NMR (500 MHz, DMSO) $\delta 11.01(\mathrm{~s}, 1 \mathrm{H}), 7.66(\mathrm{bs}, 3 \mathrm{H}), 7.28(\mathrm{t}, J=7.7 \mathrm{~Hz}, 1 \mathrm{H}), 6.93(\mathrm{~d}, J=7.3 \mathrm{~Hz}$, $1 \mathrm{H}), 6.74(\mathrm{~d}, J=8.0 \mathrm{~Hz}, 1 \mathrm{H}), 5.12(\mathrm{dd}, J=13.3,5.1 \mathrm{~Hz}, 1 \mathrm{H}), 4.23(\mathrm{~d}, J=17.1 \mathrm{~Hz}$, $1 \mathrm{H}), 4.12(\mathrm{~d}, J=17.1 \mathrm{~Hz}, 1 \mathrm{H}), 3.20-3.01(\mathrm{~m}, 2 \mathrm{H}), 2.99-2.85(\mathrm{~m}, 1 \mathrm{H}), 2.83-2.69$ $(\mathrm{m}, 2 \mathrm{H}), 2.66-2.58(\mathrm{~m}, 1 \mathrm{H}), 2.35-2.23(\mathrm{~m}, 1 \mathrm{H}), 2.11-1.95(\mathrm{~m}, 1 \mathrm{H}), 1.65-1.43(\mathrm{~m}$ 4H), $1.43-1.25(\mathrm{~m}, 6 \mathrm{H}) ;{ }^{13} \mathrm{C}$ NMR (126 MHz, DMSO) $\delta 173.38,171.74,169.35$, $158.85(\mathrm{q}, J=35.8 \mathrm{~Hz}), 144.14,132.54,129.68,127.01,116.31$ (q, $J=292.4 \mathrm{~Hz})$, $112.28,110.49,51.95,46.20,43.24,39.29,31.71,29.16,28.98,28.95,27.45,26.99$, 
26.23, 23.30. HRMS (ESI) m/z: calcd for $\mathrm{C}_{21} \mathrm{H}_{31} \mathrm{~N}_{4} \mathrm{O}_{3}{ }^{+}[\mathrm{M}+\mathrm{H}]^{+}, 387.2391$; found, 387.2382 .

\section{General procedure for the synthesis of compounds $\mathbf{1 0}$.}

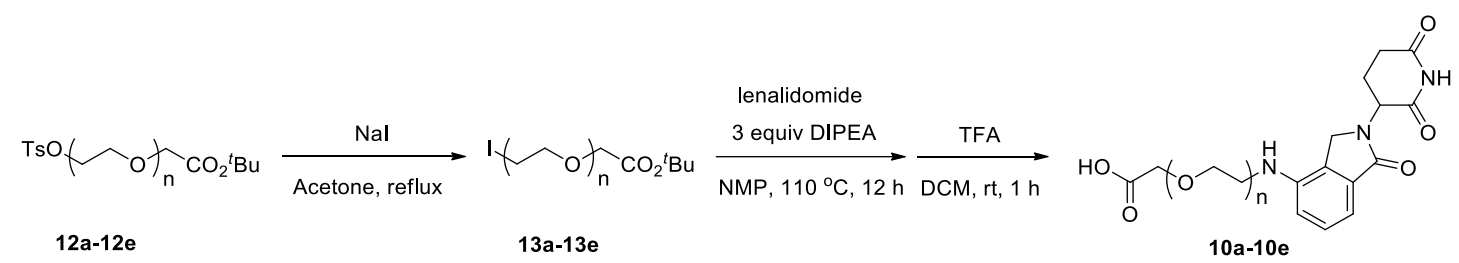

To a stirred solution of $\mathrm{NaI}$ ( 2.0 equiv) in acetone $(5 \mathrm{~mL})$ were added linkers $(\mathbf{1 2}, 1.0$ equiv). Then the mixture was refluxed at $60{ }^{\circ} \mathrm{C}$ for $2 \mathrm{~h}$. After the mixture was filtered, the filtrate was concentrated in vacuo, and the residue was used directly in the next step. To a stirred solution of iodides 13 (1.0 equiv) in NMP $(5 \mathrm{~mL})$ were added DIPEA (3.0 equiv) and lenalidomide (0.8 equiv). Then the resulting mixture was stirred at $110^{\circ} \mathrm{C}$ for $12 \mathrm{~h}$. When the reaction was complete, the crude mixture was purified by $\mathrm{C} 18$ (eluent: with $10 \%-100 \%$ (v1:v2) acetonitrile in water) to afford intermediate tert-butyl esters. To a mixture of intermediate tert-butyl esters in DCM $(4 \mathrm{~mL})$, TFA $(2 \mathrm{~mL})$ was added and stirred for $1 \mathrm{~h}$ at $25^{\circ} \mathrm{C}$. When the reaction was completed, the crude mixture was evaporated under the reduced pressure, the residue was purified by freeze-drying to afford target compounds (10).

\section{Characterization data of products 10 .}<smiles>O=C(O)COCCNc1cccc2c1CN(C1CCC(=O)NC1=O)C2=O</smiles>

2-(2-((2-(2,6-dioxopiperidin-3-yl)-1-oxoisoindolin-4-yl)amino)ethoxy)acetic acid (10a). The crude product was purified by C18 (eluent: with 10\%-100\% (v1:v2) 
acetonitrile in water). (yellow solid, $134 \mathrm{mg}, 77 \%){ }^{1} \mathrm{H}$ NMR (500 MHz, DMSO) $\delta$ $11.00(\mathrm{~s}, 1 \mathrm{H}), 7.29$ (t, $J=7.7 \mathrm{~Hz}, 1 \mathrm{H}), 6.95$ (d, $J=6.9 \mathrm{~Hz}, 1 \mathrm{H}), 6.80$ (d, $J=8.0 \mathrm{~Hz}$, 1H), $5.12(\mathrm{dd}, J=13.3,5.1 \mathrm{~Hz}, 1 \mathrm{H}), 4.24$ (d, $J=17.1 \mathrm{~Hz}, 1 \mathrm{H}), 4.13(\mathrm{~d}, J=17.0 \mathrm{~Hz}$, 1H), $4.02(\mathrm{~s}, 2 \mathrm{H}), 3.65(\mathrm{t}, J=5.9 \mathrm{~Hz}, 2 \mathrm{H}), 3.32(\mathrm{t}, J=5.9 \mathrm{~Hz}, 2 \mathrm{H}), 2.97-2.89(\mathrm{~m}$, 1H), $2.65-2.58(\mathrm{~m}, 1 \mathrm{H}), 2.33-2.25(\mathrm{~m}, 1 \mathrm{H}), 2.06-2.02(\mathrm{~m}, 1 \mathrm{H}) ;{ }^{13} \mathrm{C} \mathrm{NMR}(126 \mathrm{MHz}$, DMSO) $\delta 173.40,172.43,171.67,169.22,143.41,132.65,129.77,127.44,113.14$, 111.42, 69.39, 67.96, 51.99, 46.17, 43.30, 31.70, 23.23. HRMS (ESI) m/z: calcd for $\mathrm{C}_{17} \mathrm{H}_{20} \mathrm{~N}_{3} \mathrm{O}_{6}{ }^{+}[\mathrm{M}+\mathrm{H}]^{+}, 362.1347$; found, 362.1344 .<smiles>O=C(O)COCCOCCNc1cccc2c1CN(C1CCC(=O)NC1=O)C2=O</smiles>

N-(2-(2-(carboxymethoxy)ethoxy)ethyl)-2-(2,6-dioxopiperidin-3-yl)-1-oxoisoindol in-4-aminium 2,2,2-trifluoroacetate (10b). (yellow solid, $139 \mathrm{mg}, 80 \%$ ) ${ }^{1} \mathrm{H}$ NMR (500 MHz, DMSO) $\delta 11.00(\mathrm{~s}, 1 \mathrm{H}), 7.33-7.24(\mathrm{~m}, 1 \mathrm{H}), 6.94(\mathrm{t}, J=8.2 \mathrm{~Hz}, 1 \mathrm{H})$, $6.81(\mathrm{~d}, J=7.9 \mathrm{~Hz}, 1 \mathrm{H}), 5.11(\mathrm{dd}, J=13.3,5.1 \mathrm{~Hz}, 1 \mathrm{H}), 4.23(\mathrm{~d}, J=17.1 \mathrm{~Hz}, 1 \mathrm{H})$, $4.14(\mathrm{~d}, J=17.1 \mathrm{~Hz}, 1 \mathrm{H}), 4.04-4.01(\mathrm{~m}, 2 \mathrm{H}), 3.62-3.56(\mathrm{~m}, 6 \mathrm{H}), 3.32(\mathrm{t}, J=5.9$ $\mathrm{Hz}, 2 \mathrm{H}), 2.95-2.88(\mathrm{~m}, 1 \mathrm{H}), 2.62(\mathrm{~d}, J=17.6 \mathrm{~Hz}, 1 \mathrm{H}), 2.35-2.28(\mathrm{~m}, 1 \mathrm{H}), 2.07-2.00$ $(\mathrm{m}, 1 \mathrm{H}) ;{ }^{13} \mathrm{C}$ NMR $(126 \mathrm{MHz}, \mathrm{DMSO}) \delta 173.38,172.14,171.70,169.28,158.82$ (q, $J$ $=38.0 \mathrm{~Hz}), 143.87,132.61,129.71,127.11,115.68$ (q, $J=289.1 \mathrm{~Hz}), 112.64,110.91$, 70.33, 70.15, 69.26, 68.07, 51.98, 46.16, 43.07, 31.71, 23.23. HRMS (ESI) m/z: calcd for $\mathrm{C}_{19} \mathrm{H}_{24} \mathrm{~N}_{3} \mathrm{O}_{7}^{+}[\mathrm{M}+\mathrm{H}]^{+}, 406.1609$; found, 406.1618.

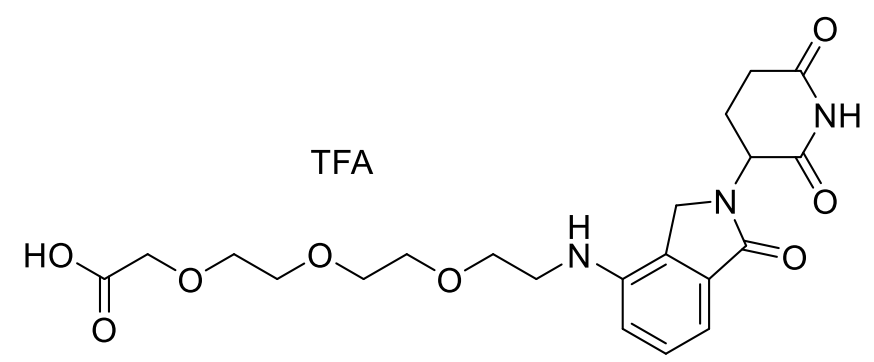

$N$-(2-(2-(2-(carboxymethoxy)ethoxy)ethoxy)ethyl)-2-(2,6-dioxopiperidin-3-yl)-1-o 
xoisoindolin-4-aminium 2,2,2-trifluoroacetate (10c). (yellow liquid, $124 \mathrm{mg}, 72 \%$ ) ${ }^{1} \mathrm{H}$ NMR (500 MHz, DMSO) $\delta 11.00$ (s, 1H), 7.29 (t, $\left.J=7.7 \mathrm{~Hz}, 1 \mathrm{H}\right), 6.94$ (d, $J=7.4$ $\mathrm{Hz}, 1 \mathrm{H}), 6.81(\mathrm{~d}, J=8.0 \mathrm{~Hz}, 1 \mathrm{H}), 5.11(\mathrm{dd}, J=13.3,5.1 \mathrm{~Hz}, 1 \mathrm{H}), 4.23(\mathrm{~d}, J=17.1 \mathrm{~Hz}$, 1H), $4.13(\mathrm{~d}, J=17.1 \mathrm{~Hz}, 1 \mathrm{H}), 4.01(\mathrm{~s}, 2 \mathrm{H}), 3.60-3.51(\mathrm{~m}, 10 \mathrm{H}), 3.34-3.30(\mathrm{~m}, 2 \mathrm{H})$, $2.97-2.87(\mathrm{~m}, 1 \mathrm{H}), 2.62(\mathrm{~d}, J=16.9 \mathrm{~Hz}, 1 \mathrm{H}), 2.36-2.28(\mathrm{~m}, 1 \mathrm{H}), 2.07-2.01(\mathrm{~m}, 1 \mathrm{H})$; ${ }^{13} \mathrm{C}$ NMR (126 MHz, DMSO) $\delta$ 172.32, 171.06, 170.65, 168.22, 157.71 (q, $J=37.5$ $\mathrm{Hz}), 142.88,131.54,128.64,125.98,114.73$ (q, $J=289.9 \mathrm{~Hz}), 111.49,109.75,69.23$, 69.17, 69.15, 69.13, 68.27, 66.97, 50.92, 45.15, 41.98, 30.65, 22.18. HRMS (ESI) m/z: calcd for $\mathrm{C}_{21} \mathrm{H}_{28} \mathrm{~N}_{3} \mathrm{O}_{8}{ }^{+}[\mathrm{M}+\mathrm{H}]^{+}, 450.1871$; found, 450.1879.<smiles>O=C(O)COCCOCCOCCOCCNc1cccc2c1CN(C1CCC(=O)NC1=O)C2=O</smiles>

$N$-(1-carboxy-2,5,8,11-tetraoxatridecan-13-yl)-2-(2,6-dioxopiperidin-3-yl)-1-oxois oindolin-4-aminium 2,2,2-trifluoroacetate (10d). (yellow liquid, $134 \mathrm{mg}, 79 \%$ ) ${ }^{1} \mathrm{H}$ NMR (500 MHz, DMSO) $\delta 11.00(\mathrm{~s}, 1 \mathrm{H}), 7.29$ (t, $J=7.7 \mathrm{~Hz}, 1 \mathrm{H}), 6.96(\mathrm{~d}, J=7.3 \mathrm{~Hz}$, $1 \mathrm{H}), 6.82(\mathrm{~d}, J=8.0 \mathrm{~Hz}, 1 \mathrm{H}), 5.11(\mathrm{dd}, J=13.3,5.1 \mathrm{~Hz}, 2 \mathrm{H}), 4.24(\mathrm{~d}, J=17.1 \mathrm{~Hz}$, $1 \mathrm{H}), 4.13(\mathrm{~d}, J=17.1 \mathrm{~Hz}, 1 \mathrm{H}), 4.01(\mathrm{~s}, 2 \mathrm{H}), 3.64-3.46(\mathrm{~m}, 14 \mathrm{H}), 3.32(\mathrm{t}, J=5.9 \mathrm{~Hz}$, 2H), $2.99-2.86(\mathrm{~m}, 1 \mathrm{H}), 2.62(\mathrm{~d}, J=16.9 \mathrm{~Hz}, 1 \mathrm{H}), 2.37-2.25(\mathrm{~m}, 1 \mathrm{H}), 2.07-2.00$ $(\mathrm{m}, 1 \mathrm{H}) ;{ }^{13} \mathrm{C}$ NMR $(126 \mathrm{MHz}, \mathrm{DMSO}) \delta 173.38,172.12,171.70,169.29,158.81$ (q, $J$ $=38.0 \mathrm{~Hz}), 143.88,132.60,129.71,127.08,115.65$ (q, $J=289.1 \mathrm{~Hz}), 112.63,110.89$, 70.28, 70.25, 70.20, 69.31, 68.02, 51.98, 46.18, 43.07, 31.71, 23.24. HRMS (ESI) m/z: calcd for $\mathrm{C}_{23} \mathrm{H}_{32} \mathrm{~N}_{3} \mathrm{O}_{9}{ }^{+}[\mathrm{M}+\mathrm{H}]^{+}, 494.2133$; found, 494.2144.<smiles>O=C(O)COCCOCCOCCOCCOCCNc1cccc2c1CN(C1CCC(=O)NC1=O)C2=O</smiles> 


\section{N-(1-carboxy-2,5,8,11,14-pentaoxahexadecan-16-yl)-2-(2,6-dioxopiperidin-3-yl)-1}

-oxoisoindolin-4-aminium 2,2,2-trifluoroacetate (10e). (yellow liquid, $127 \mathrm{mg}, 75 \%$ ) ${ }^{1} \mathrm{H}$ NMR (500 MHz, DMSO) $\delta 11.01(\mathrm{~s}, 1 \mathrm{H}), 7.29(\mathrm{t}, J=7.7 \mathrm{~Hz}, 1 \mathrm{H}), 6.95(\mathrm{~d}, J=6.9$ $\mathrm{Hz}, 1 \mathrm{H}), 6.80(\mathrm{~d}, J=6.9 \mathrm{~Hz}, 1 \mathrm{H}), 5.11(\mathrm{dd}, J=13.3,5.1 \mathrm{~Hz}, 1 \mathrm{H}), 4.24(\mathrm{~d}, J=17.1 \mathrm{~Hz}$, $1 \mathrm{H}), 4.14(\mathrm{~d}, J=17.1 \mathrm{~Hz}, 1 \mathrm{H}), 4.01(\mathrm{~s}, 2 \mathrm{H}), 3.62-3.46(\mathrm{~m}, 18 \mathrm{H}), 3.32(\mathrm{t}, J=5.9 \mathrm{~Hz}$, 2H), 2.96-2.88 (m, 1H), $2.62(\mathrm{~d}, J=16.6 \mathrm{~Hz}, 1 \mathrm{H}), 2.37-2.25(\mathrm{~m}, 1 \mathrm{H}), 2.08-2.00$ $(\mathrm{m}, 1 \mathrm{H}) ;{ }^{13} \mathrm{C}$ NMR $(126 \mathrm{MHz}, \mathrm{DMSO}) \delta 172.33,171.06,170.65,168.23,157.77$ (q, $J$ $=38.2 \mathrm{~Hz}), 142.81,131.56,128.65,126.05,114.56$ (q, $J=288.9 \mathrm{~Hz}), 111.61,109.86$, $69.23,69.21,69.17,69.14,68.26,66.98,50.93,45.13,42.04,30.66,22.21$. HRMS (ESI) $\mathrm{m} / \mathrm{z}$ : calcd for $\mathrm{C}_{25} \mathrm{H}_{36} \mathrm{~N}_{3} \mathrm{O}_{10}{ }^{+}[\mathrm{M}+\mathrm{H}]^{+}, 538.2395$; found, 538.2403.

\section{Procedure for the synthesis of compounds 3.}

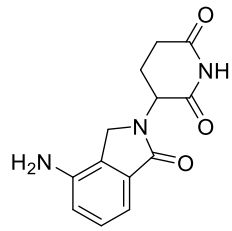

$1 \mathrm{a}$

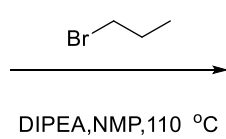

DIPEA,NMP $110{ }^{\circ} \mathrm{C}$

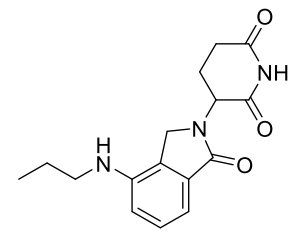

$3 \mathbf{a}$

To a stirred solution of 3-(4-amino-1-oxoisoindolin-2-yl)piperidine-2,6-dione (20mg, 0.073mmol, 1.0 equiv) in NMP ( $2 \mathrm{~mL})$ were added DIPEA (29.9 mg, 0.219 mmol, 3.0 equiv) and 1-Bromopropane (18.9 mg, $0.0876 \mathrm{mmol}, 1.2$ equiv). Then the resulting mixture was stirred at $110{ }^{\circ} \mathrm{C}$ for $2 \mathrm{~h}$. When the reaction was completed, the crude mixture was purified by HPLC Preparation on C18 (eluent: with 10\% - 100\% (v1:v2) acetonitrile in water) and freeze-drying to obtain the target compound 3-(1-oxo-4-(propylamino)isoindolin-2-yl)piperidine-2,6-dione $(18.5 \mathrm{mg}, 84 \%)$ as a yellow solid. ${ }^{1} \mathrm{H}$ NMR (500 MHz, DMSO) $\delta 11.00(\mathrm{~s}, 1 \mathrm{H}), 7.28(\mathrm{t}, J=7.7 \mathrm{~Hz}, 1 \mathrm{H})$, $6.92(\mathrm{~d}, J=7.4 \mathrm{~Hz}, 1 \mathrm{H}), 6.74(\mathrm{~d}, J=8.0 \mathrm{~Hz}, 1 \mathrm{H}), 5.58(\mathrm{~s}, 1 \mathrm{H}), 5.11(\mathrm{dd}, J=13.3,5.1$ $\mathrm{Hz}, 1 \mathrm{H}), 4.23(\mathrm{~d}, J=17.1 \mathrm{~Hz}, 1 \mathrm{H}), 4.13(\mathrm{~d}, J=17.1 \mathrm{~Hz}, 1 \mathrm{H}), 3.09$ (t, $J=6.7 \mathrm{~Hz}, 2 \mathrm{H})$, $2.98-2.86(\mathrm{~m}, 1 \mathrm{H}), 2.66-2.58(\mathrm{~m}, 1 \mathrm{H}), 2.35-2.24(\mathrm{~m}, 1 \mathrm{H}), 2.08-1.98(\mathrm{~m}, 1 \mathrm{H})$, 
$1.64-1.52(\mathrm{~m}, 2 \mathrm{H}), 0.94(\mathrm{t}, J=7.4 \mathrm{~Hz}, 3 \mathrm{H}) ;{ }^{13} \mathrm{C} \mathrm{NMR}(126 \mathrm{MHz}, \mathrm{DMSO}) \delta 173.41$, $171.73,169.39,144.23$, 132.51, 129.69, 126.91, 112.25, 110.39, 51.96, 46.21, 45.02, 31.71, 23.28, 22.22, 12.07. HRMS (ESI) m/z: calcd for $\mathrm{C}_{16} \mathrm{H}_{20} \mathrm{~N}_{3} \mathrm{O}_{3}{ }^{+}[\mathrm{M}+\mathrm{H}]^{+}$, 302.1499; found, 302.1508.

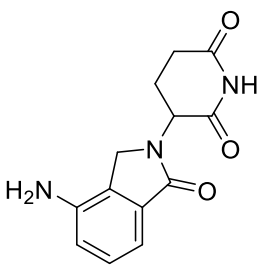

$1 \mathrm{a}$

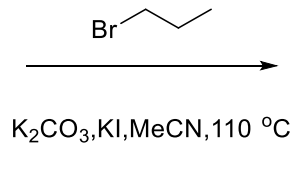

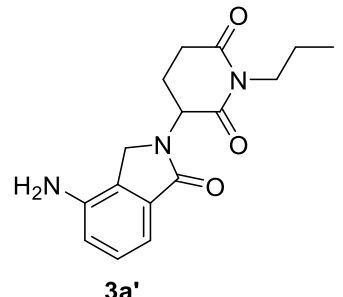

$3 a^{\prime}$

To a stirred solution of 3-(4-amino-1-oxoisoindolin-2-yl)piperidine-2,6-dione (20mg, $0.073 \mathrm{mmol}, 1.0$ equiv) in $\mathrm{MeCN}(2 \mathrm{~mL})$ were added $\mathrm{K}_{2} \mathrm{CO}_{3}(21.3 \mathrm{mg}, 0.146 \mathrm{mmol}, 2$ equiv), KI (3.8 mg, $0.0146 \mathrm{mmol}, 0.2$ equiv) and 1-Bromopropane (18.9 mg, 0.088 mmol, 1.2 equiv). Then the resulting mixture was stirred at $110{ }^{\circ} \mathrm{C}$ for $2 \mathrm{~h}$. When the reaction was complete, the crude mixture was purified by HPLC Preparation on C18 (eluent: with $10 \%-100 \%(\mathrm{v} 1: \mathrm{v} 2)$ acetonitrile in water) and freeze-drying to obtain the target compound 3-(4-amino-1-oxoisoindolin-2-yl)-1-propylpiperidine-2,6-dione $(12.8 \mathrm{mg}, 58 \%)$ as a yellow solid. ${ }^{1} \mathrm{H}$ NMR (500 MHz, DMSO) $\delta 7.23(\mathrm{t}, J=7.6 \mathrm{~Hz}, 1 \mathrm{H}), 6.98(\mathrm{~d}, J=$ $6.9 \mathrm{~Hz}, 1 \mathrm{H}), 6.86(\mathrm{~d}, J=7.6 \mathrm{~Hz}, 1 \mathrm{H}), 6.10-6.21(\mathrm{~s}, 2 \mathrm{H}), 5.18(\mathrm{dd}, J=13.4,5.1 \mathrm{~Hz}$, 1H), $4.23(\mathrm{~d}, J=16.9 \mathrm{~Hz}, 1 \mathrm{H}), 4.11(\mathrm{~d}, J=16.9 \mathrm{~Hz}, 1 \mathrm{H}), 3.68-3.50(\mathrm{~m}, 2 \mathrm{H}), 3.08-$ $2.96(\mathrm{~m}, 1 \mathrm{H}), 2.83-2.71(\mathrm{~m}, 1 \mathrm{H}), 2.35-2.24(\mathrm{~m}, 1 \mathrm{H}), 2.09-1.99(\mathrm{~m}, 1 \mathrm{H}), 1.52-$ $1.40(\mathrm{~m}, 2 \mathrm{H}), 0.83(\mathrm{t}, J=7.5 \mathrm{~Hz}, 3 \mathrm{H}) .{ }^{13} \mathrm{C} \mathrm{NMR}(126 \mathrm{MHz}, \mathrm{DMSO}) \delta 172.23,171.09$, $169.17,142.22,132.88,129.47,127.26,118.13,112.43,52.61,46.05,41.50,31.92$, 22.53, 21.23, 11.69. HRMS (ESI) $\mathrm{m} / \mathrm{z}$ : calcd for $\mathrm{C}_{16} \mathrm{H}_{20} \mathrm{~N}_{3} \mathrm{O}_{3}{ }^{+}[\mathrm{M}+\mathrm{H}]^{+}, 302.1499$; found, 302.1509 . 


\section{Procedure for the synthesis of compound SIAIS213110.}

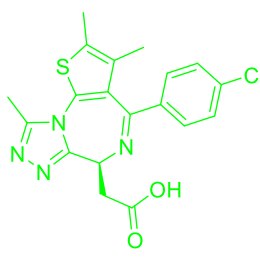

JQ1 precursor

To

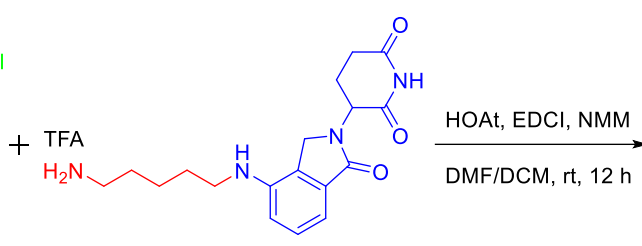

$9 c$

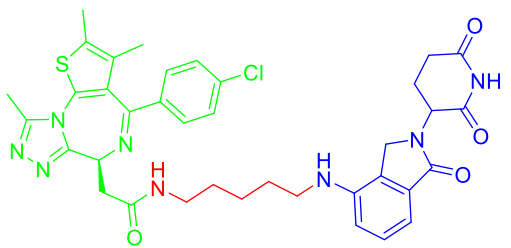

SIAIS213110

stirred

of

(S)-2-(4-(4-chlorophenyl)-2,3,9-trimethyl-6H-thieno[3,2-f][1,2,4]triazolo[4,3-a][1,4]d iazepin-6-yl)acetic acid (20 mg, $0.05 \mathrm{mmol}, 1.0$ equiv) and 9c $(17.2 \mathrm{mg}, 0.05 \mathrm{mmol}$, 1.0 equiv) in DMF ( $2 \mathrm{~mL})$ were added HOAt (13.6 mg, $0.1 \mathrm{mmol}, 2$ equiv), EDCI (19.2 mg, $0.1 \mathrm{mmol}, 2$ equiv) and NMM (25.3 mg, $0.25 \mathrm{mmol}, 5$ equiv). Then the resulting mixture was stirred at room temperature for $12 \mathrm{~h}$. When the reaction was complete, the crude mixture was purified by HPLC Preparation on C18 (eluent: with $10 \%-100 \%(\mathrm{v} 1: \mathrm{v} 2)$ acetonitrile in water) and freeze-drying to obtain the target compound SIAIS 213110 2-((S)-4-(4-chlorophenyl)-2,3,9-trimethyl-6H-thieno[3,2-f][1,2,4]triazolo[4,3-a][1, 4]diazepin-6-yl)-N-(5-((2-(2,6-dioxopiperidin-3-yl)-1-oxoisoindolin-4-yl)amino)pe ntyl)acetamide (21.4 $\mathrm{mg}, 59 \%)$ as a yellow solid. ${ }^{1} \mathrm{H}$ NMR (500 MHz, MeOD) $\delta 7.45$ $-7.27(\mathrm{~m}, 5 \mathrm{H}), 7.06(\mathrm{dd}, J=7.4,3.0 \mathrm{~Hz}, 1 \mathrm{H}), 6.79(\mathrm{dd}, J=8.0,5.0 \mathrm{~Hz}, 1 \mathrm{H}), 5.07$ (ddd, $J=30.3,13.3,5.2 \mathrm{~Hz}, 1 \mathrm{H}), 4.67-4.59$ (m, 1H), $4.31-4.19$ (m, 2H), $3.45-$ $3.32(\mathrm{~m}, 2 \mathrm{H}), 3.29-3.23(\mathrm{~m}, 2 \mathrm{H}), 3.18(\mathrm{dt}, J=6.7,5.3 \mathrm{~Hz}, 2 \mathrm{H}), 2.86(\mathrm{dtd}, J=18.9$, 13.6, $5.4 \mathrm{~Hz}, 1 \mathrm{H}), 2.75-2.64(\mathrm{~m}, 4 \mathrm{H}), 2.45-2.33(\mathrm{~m}, 4 \mathrm{H}), 2.09$ (ddtd, $J=18.1,12.7$, 5.2, $2.3 \mathrm{~Hz}, 1 \mathrm{H}), 1.72(\mathrm{ddd}, J=21.0,13.9,6.7 \mathrm{~Hz}, 2 \mathrm{H}), 1.62$ (t, $J=11.2 \mathrm{~Hz}, 5 \mathrm{H}), 1.56$ - 1.47 (m, 2H). ${ }^{13} \mathrm{C}$ NMR (126 MHz, MeOD) $\delta$ 173.26, 171.36, 171.27, 171.01, $170.81,165.06,155.58,150.93,143.51,136.75,136.48,132.08,131.60,130.68$, $130.58,129.97,129.94,129.25,128.41,128.37,126.78,112.72,110.78,53.89,52.12$, $46.00,43.10,38.73,37.35,30.95,28.89,28.21,23.94,22.83,13.00,11.55,10.20$. HRMS (ESI) m/z: calcd for $\mathrm{C}_{37} \mathrm{H}_{40} \mathrm{ClN}_{8} \mathrm{O}_{4} \mathrm{~S}^{+}[\mathrm{M}+\mathrm{H}]^{+}$, 727.2576; found, 727.2573. 
$8 a$

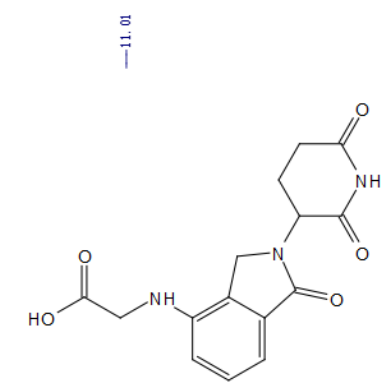

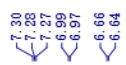

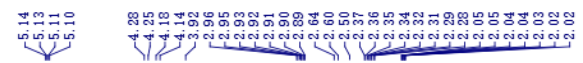

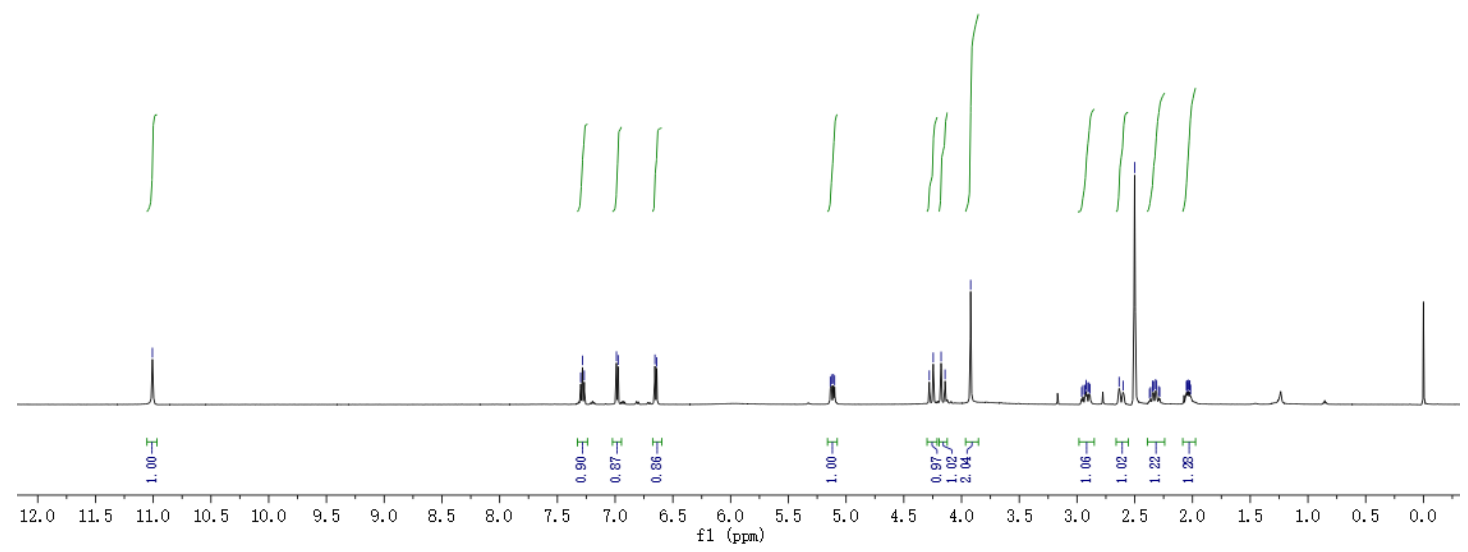

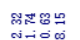

천형

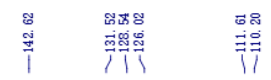

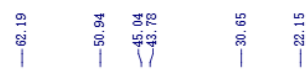<smiles>O=C(O)CNc1cccc2c1CN(C1CCC(=O)CC1=O)C2=O</smiles>

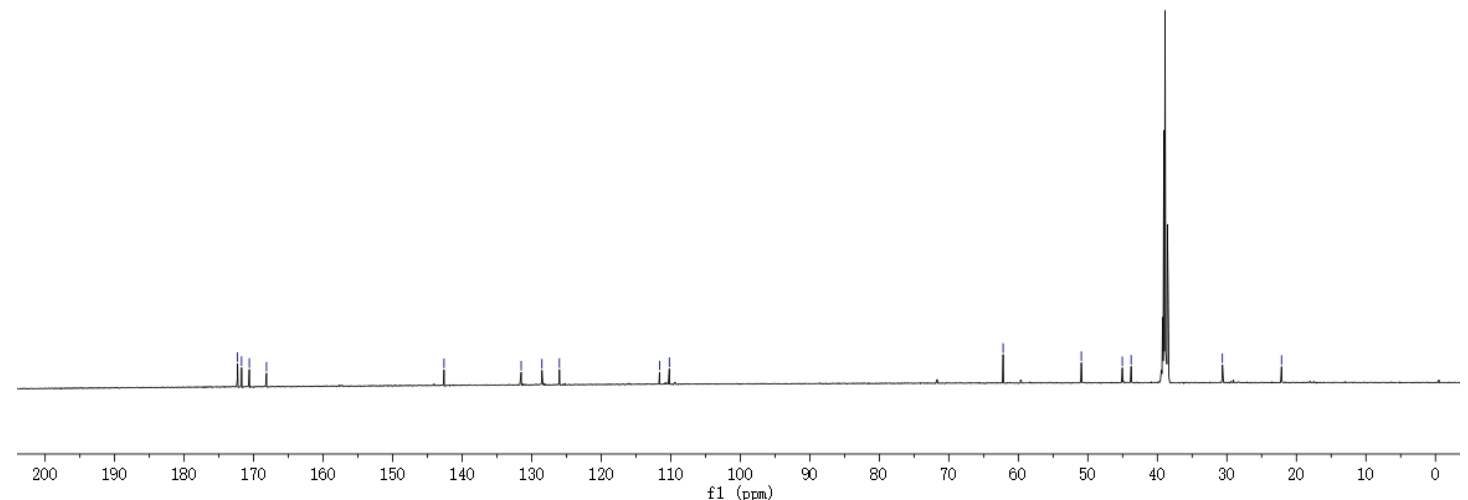


8b

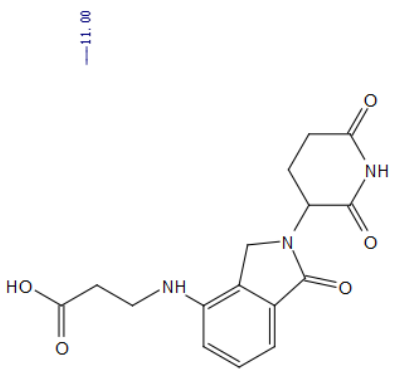

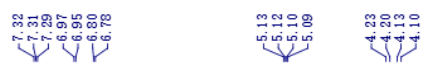

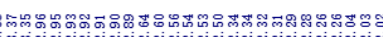

ตุin่
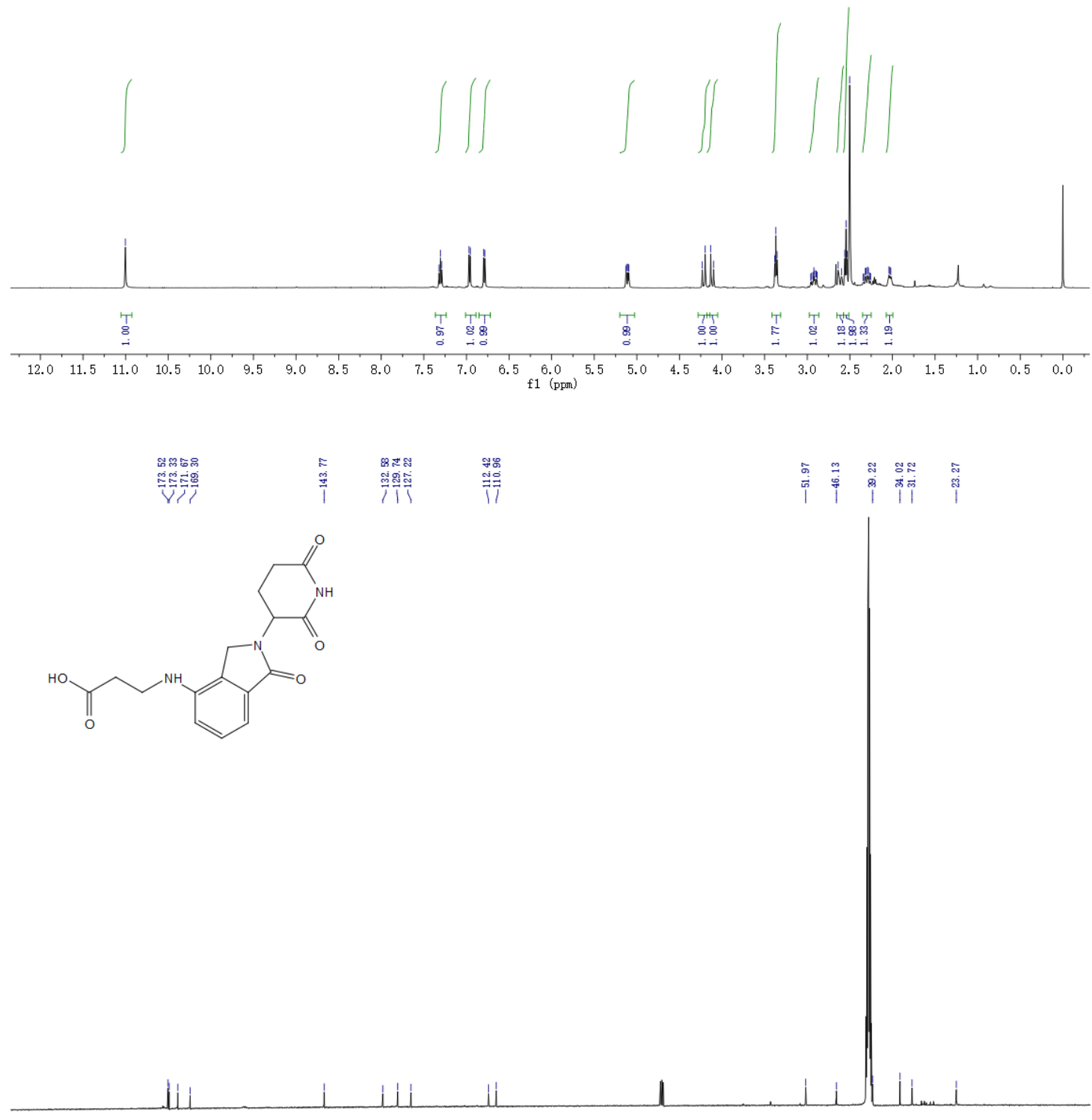

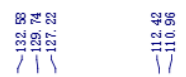

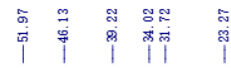

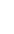

200

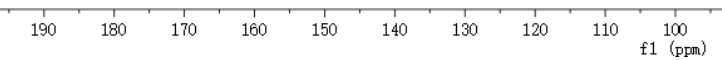


8c
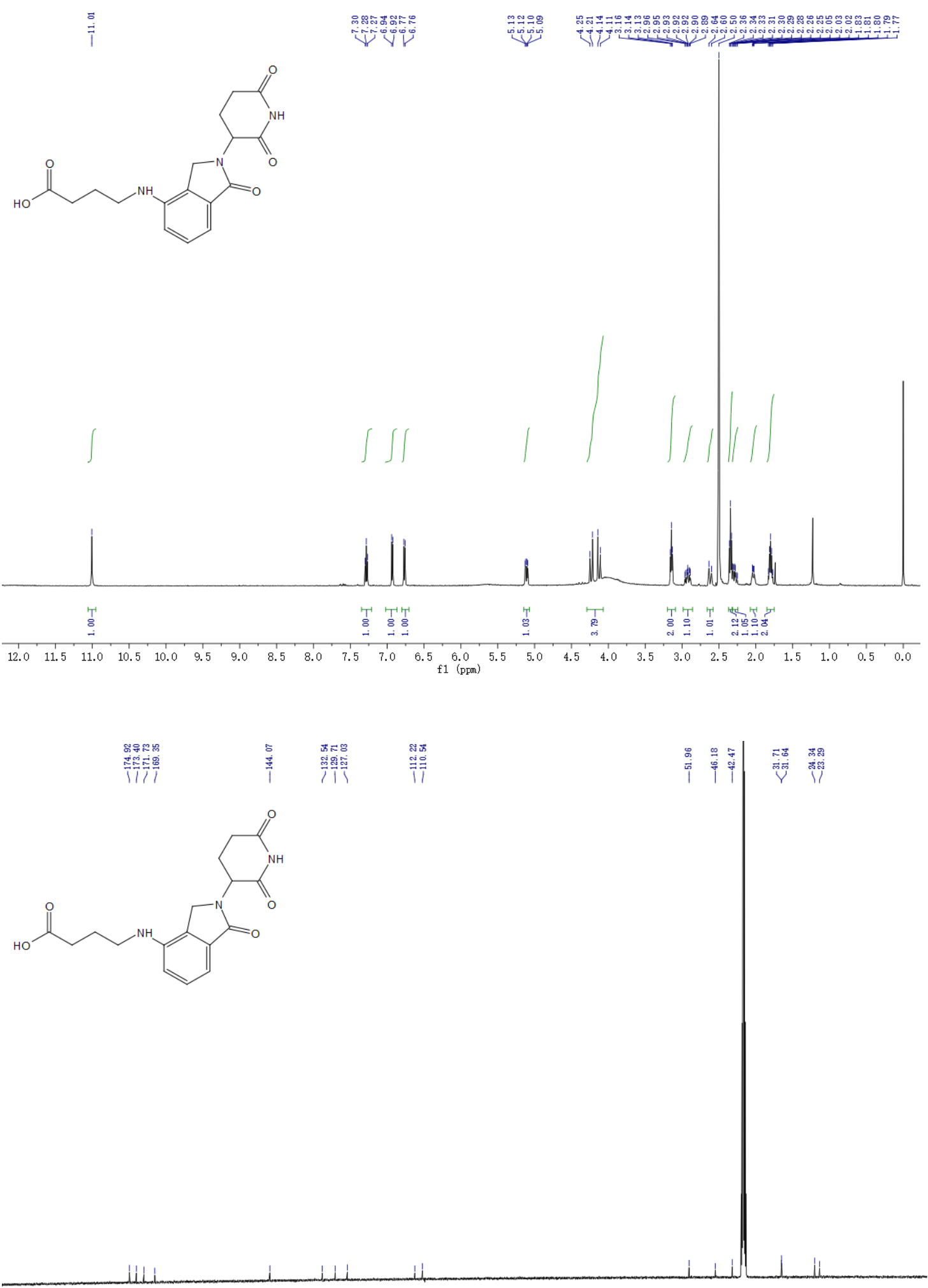

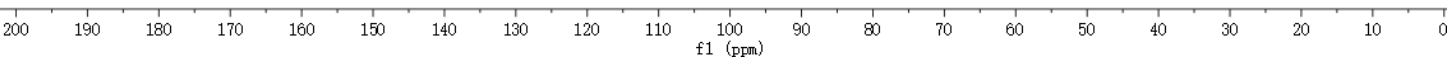


8d
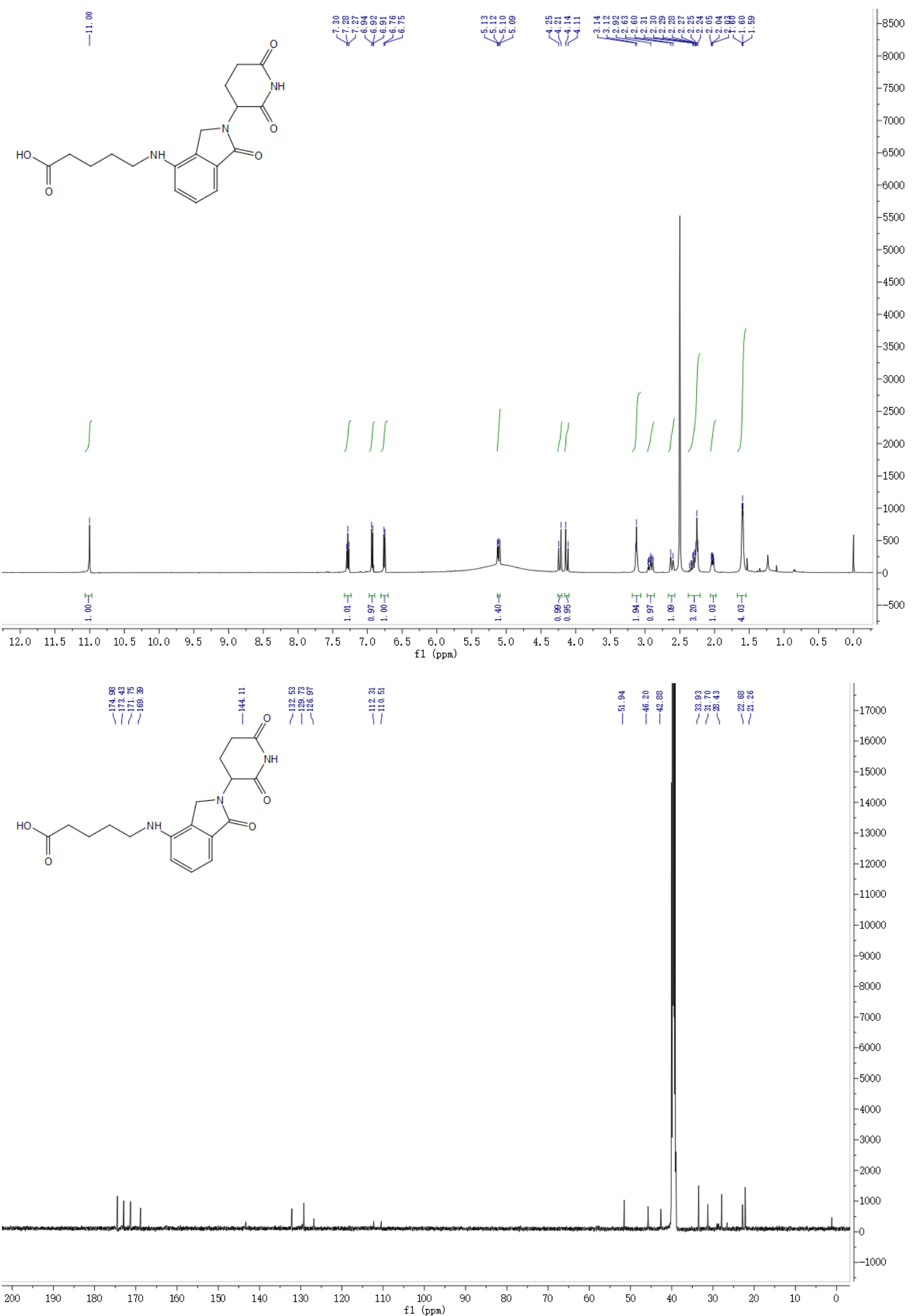
8e

$\stackrel{\vec{i}}{\vec{i}}$

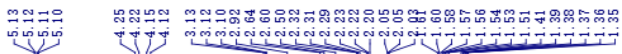<smiles>C[C@H]1C(=O)CCC(N2Cc3c(NCCCCCC(=O)O)cccc3C2=O)C1C(=O)O</smiles>

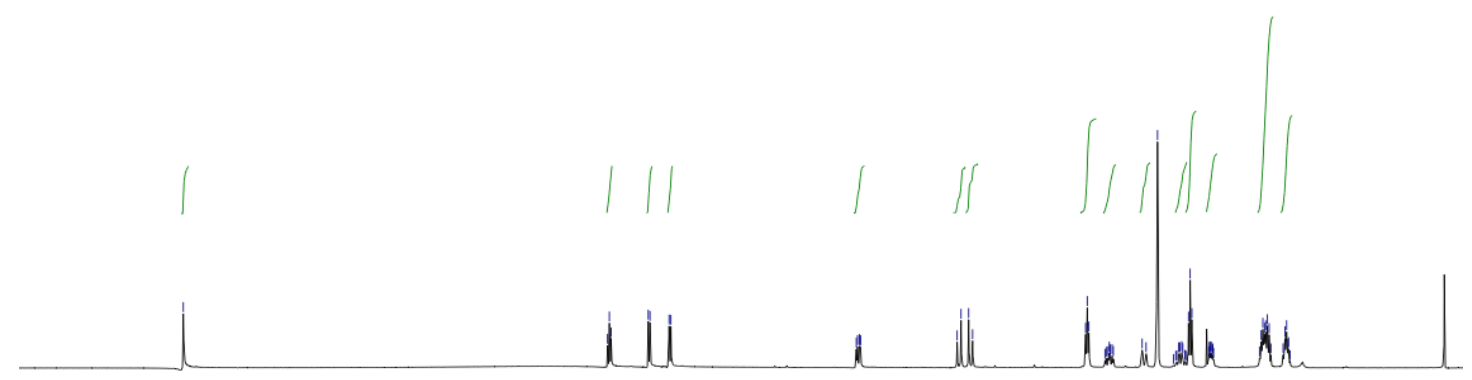

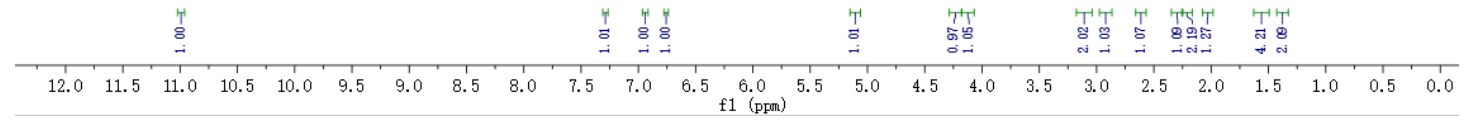

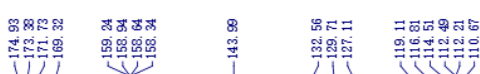

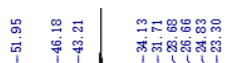

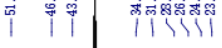<smiles>O=C(O)CCCCCNc1cccc2c1CN(C1CCCNC1C(=O)O)C2=O</smiles>

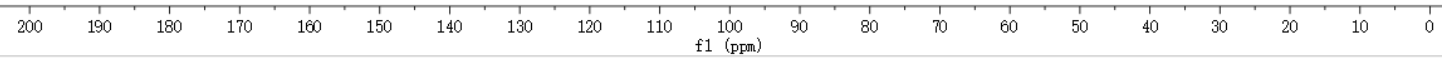


<smiles>O=C(O)CCCCCCNc1cccc2c1CN(C1CCC(=O)[C@@H]3CCCCC13)C(=O)C2</smiles>

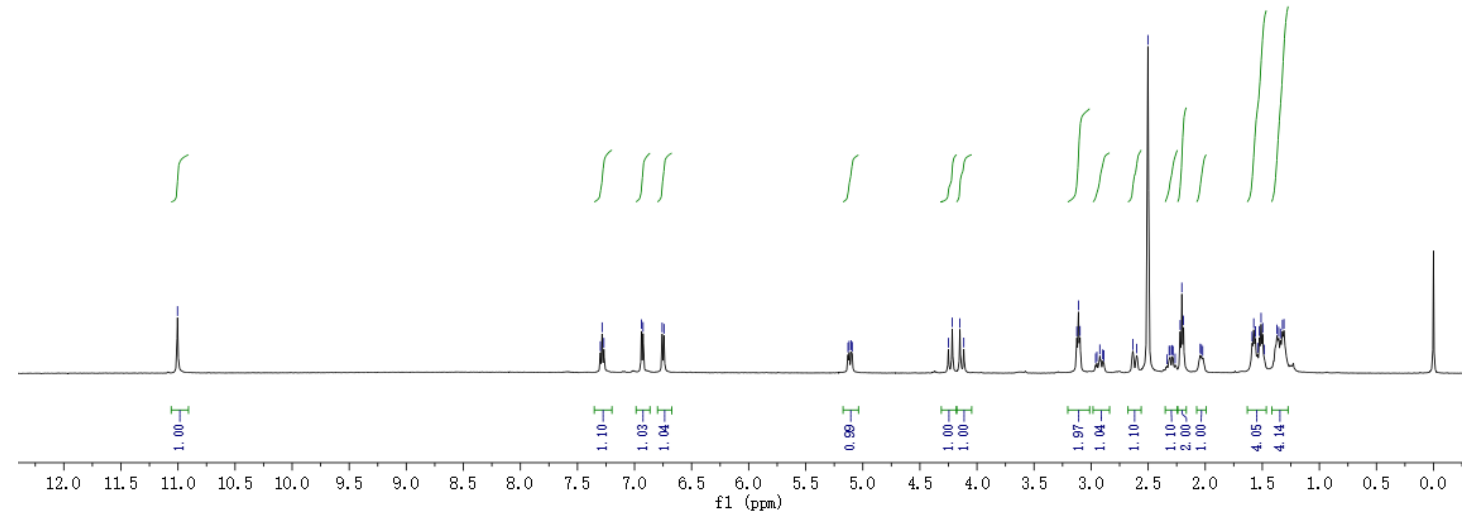<smiles>CC1CCC(N2Cc3c(NCCCCCCC(=O)O)cccc3C2=O)C(=O)N1</smiles>

لì

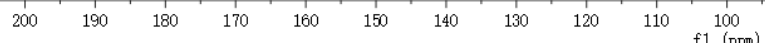




\section{9a}
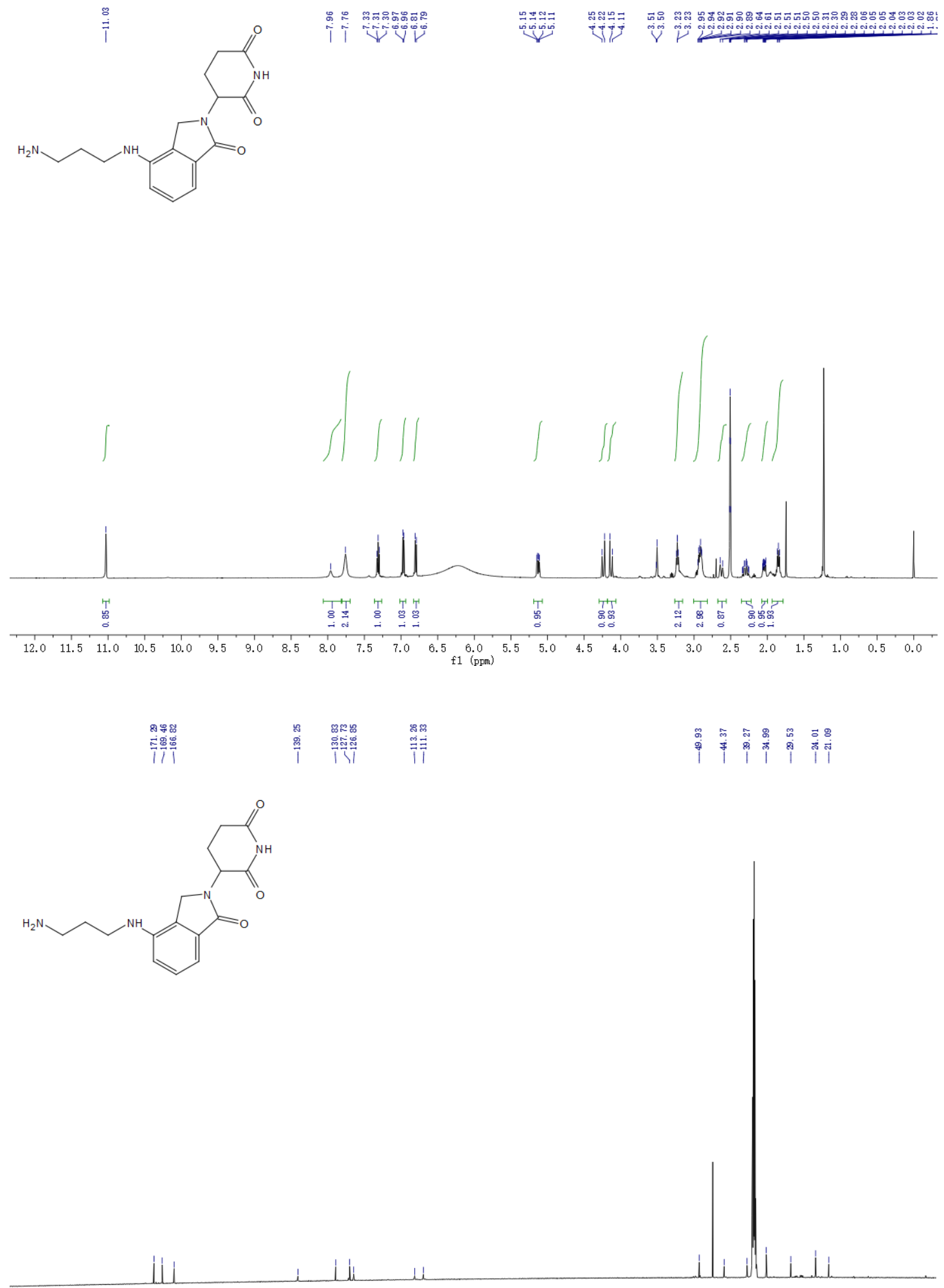

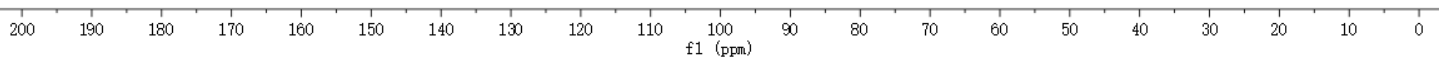


9b

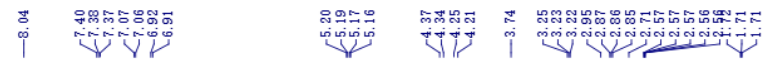<smiles>CC1CCC(N2Cc3ccccc3C(=O)N2)C(=O)N1</smiles>
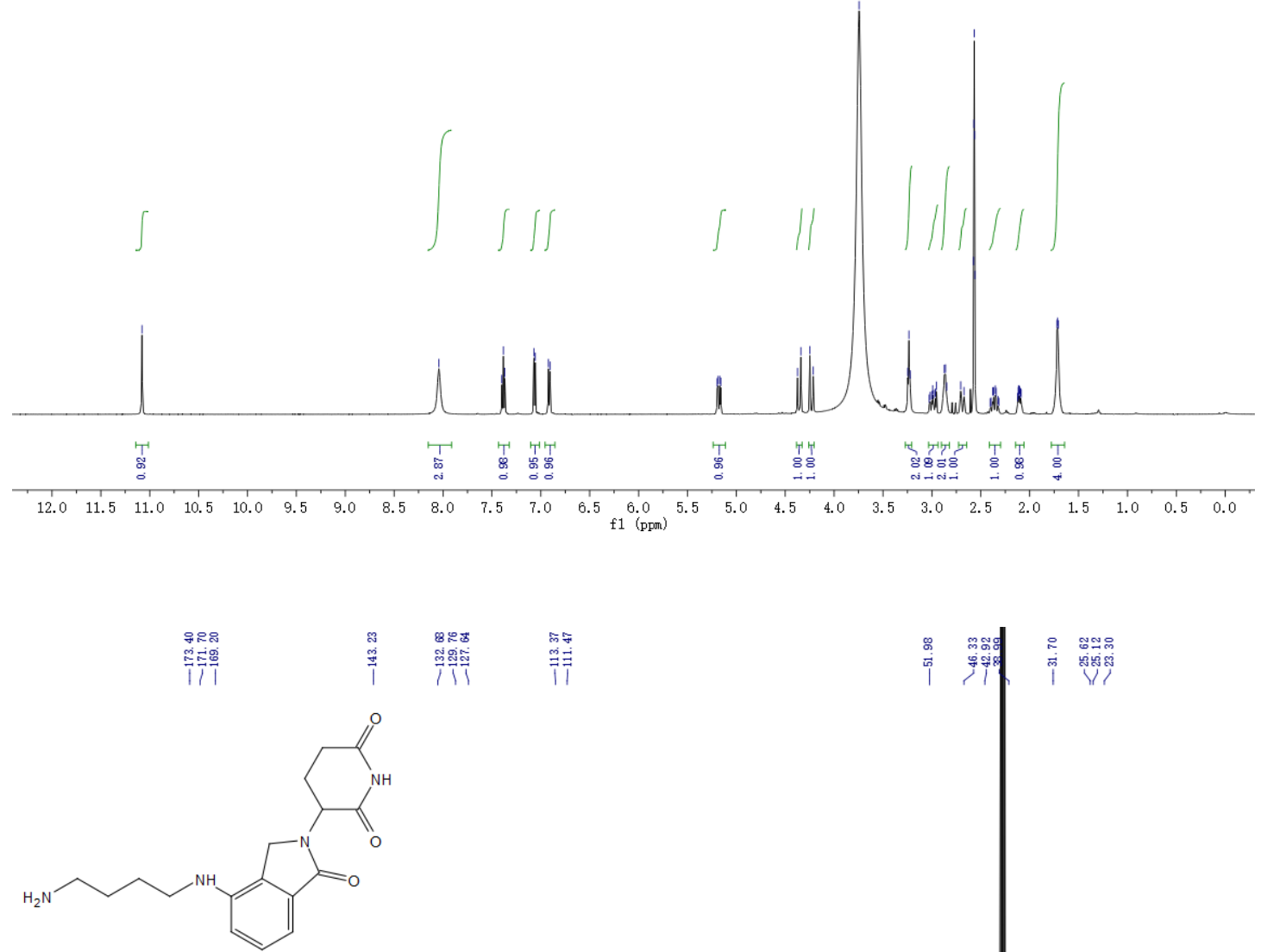
9c

$\stackrel{\overrightarrow{5}}{\vec{i}}$

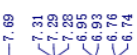

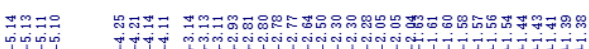

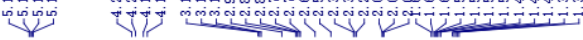

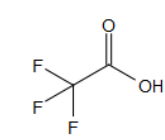

(N)

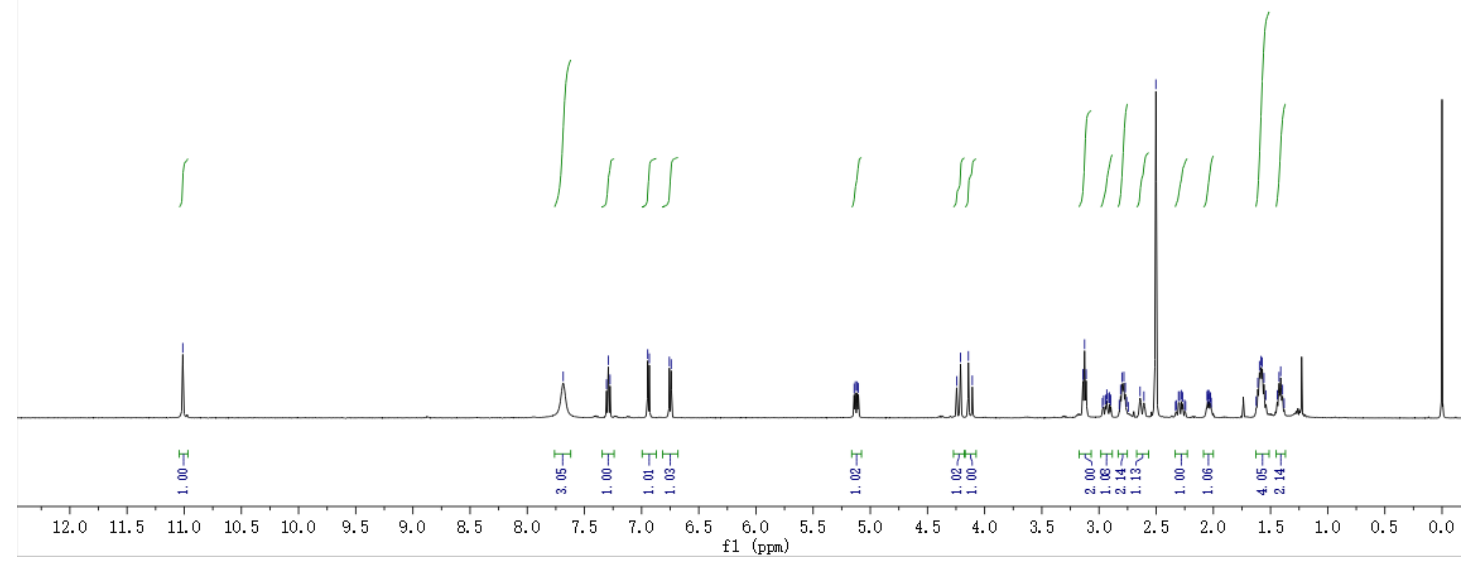

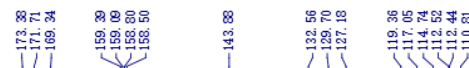

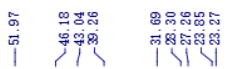

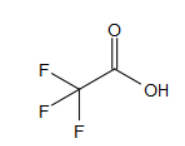<smiles>O=C1CCC(N2CCCc3ccccc3C2)C(=O)N1</smiles>

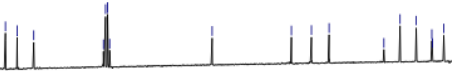
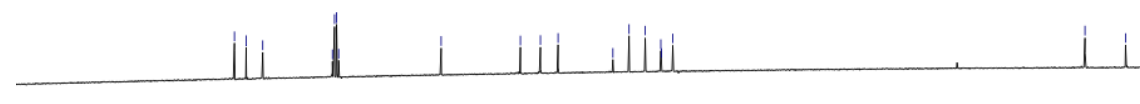

$200 \quad 190$

$\cdot 17$

$160 \div 150$

${ }_{130}^{1} 120$

$110 \underset{f 1(\mathrm{prm})}{100}$ 
<smiles>NCCCCCCNc1cccc2c1CN(C1CCC(=O)NC1=O)C2=O</smiles>

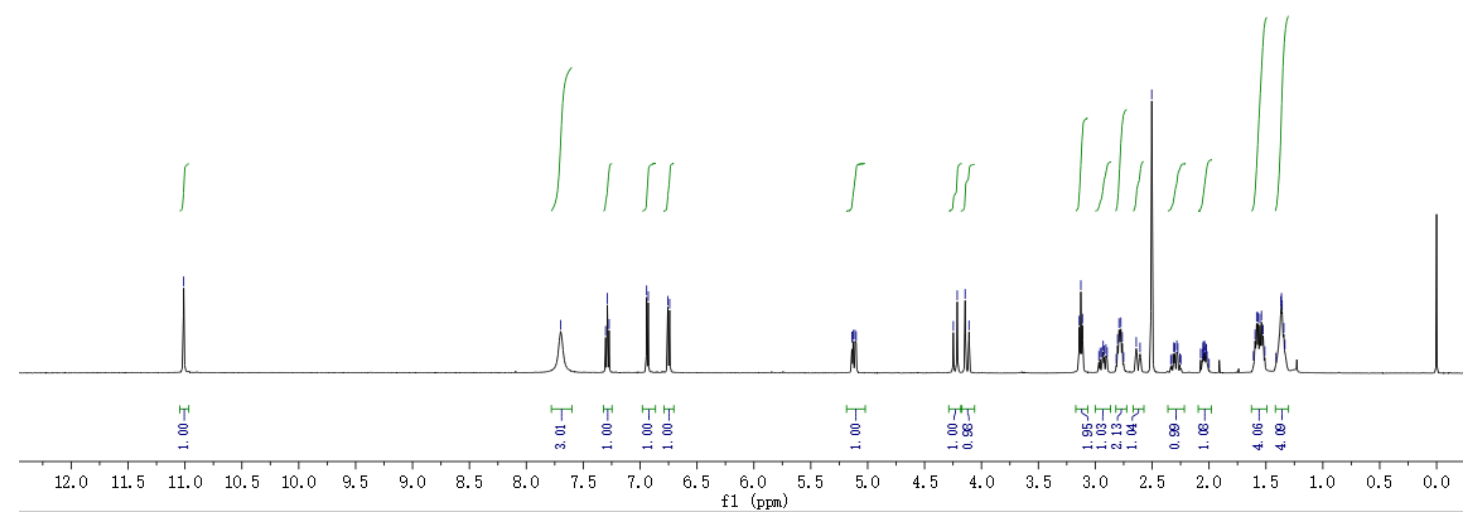

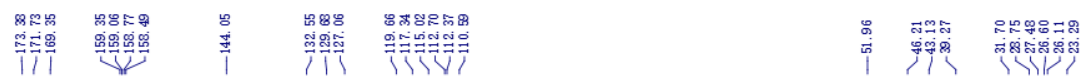
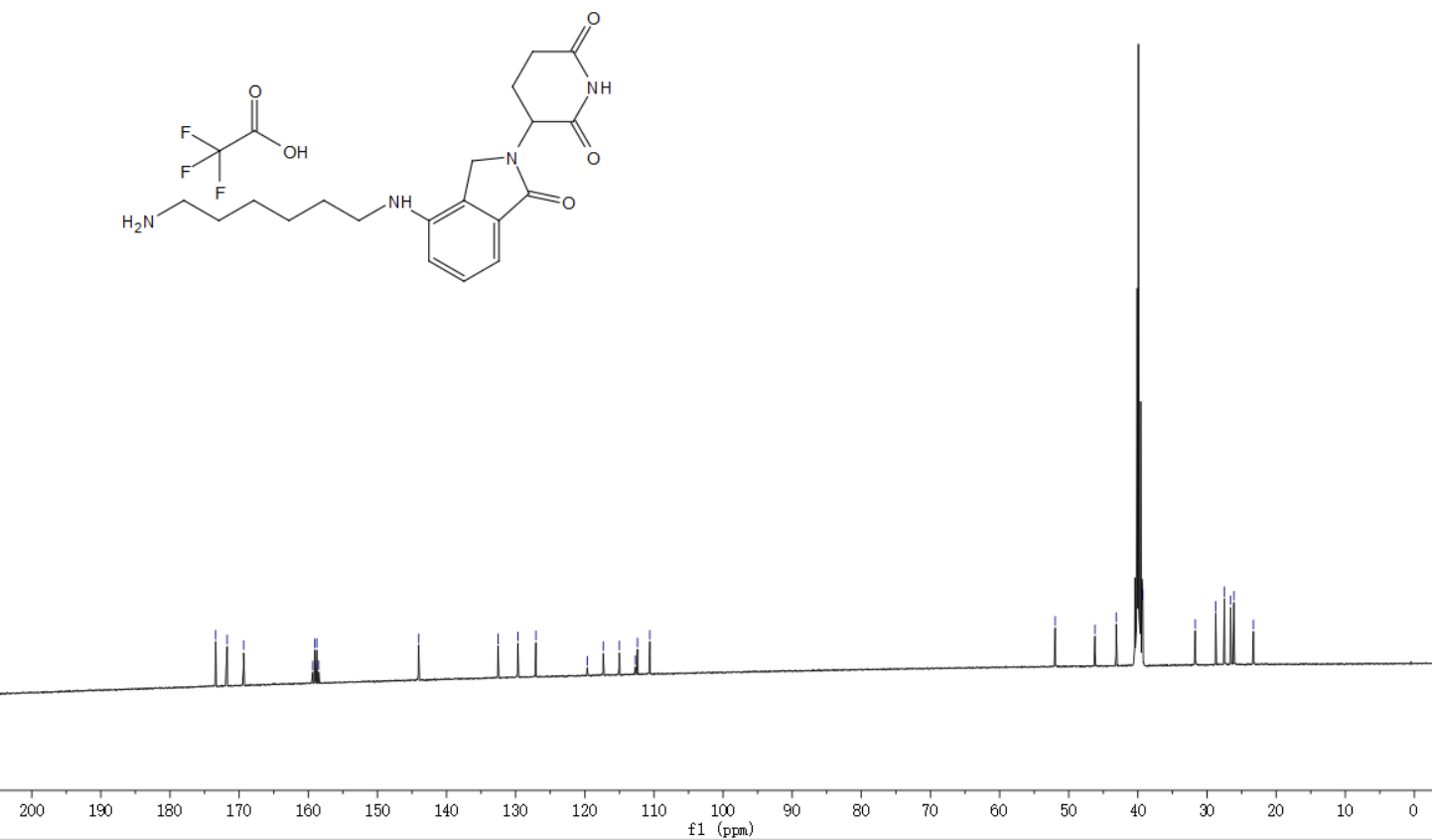
9e<smiles>C=C1CCC(N2Cc3c(NCCCCCCCN)cccc3C2=O)C(=O)N1</smiles>
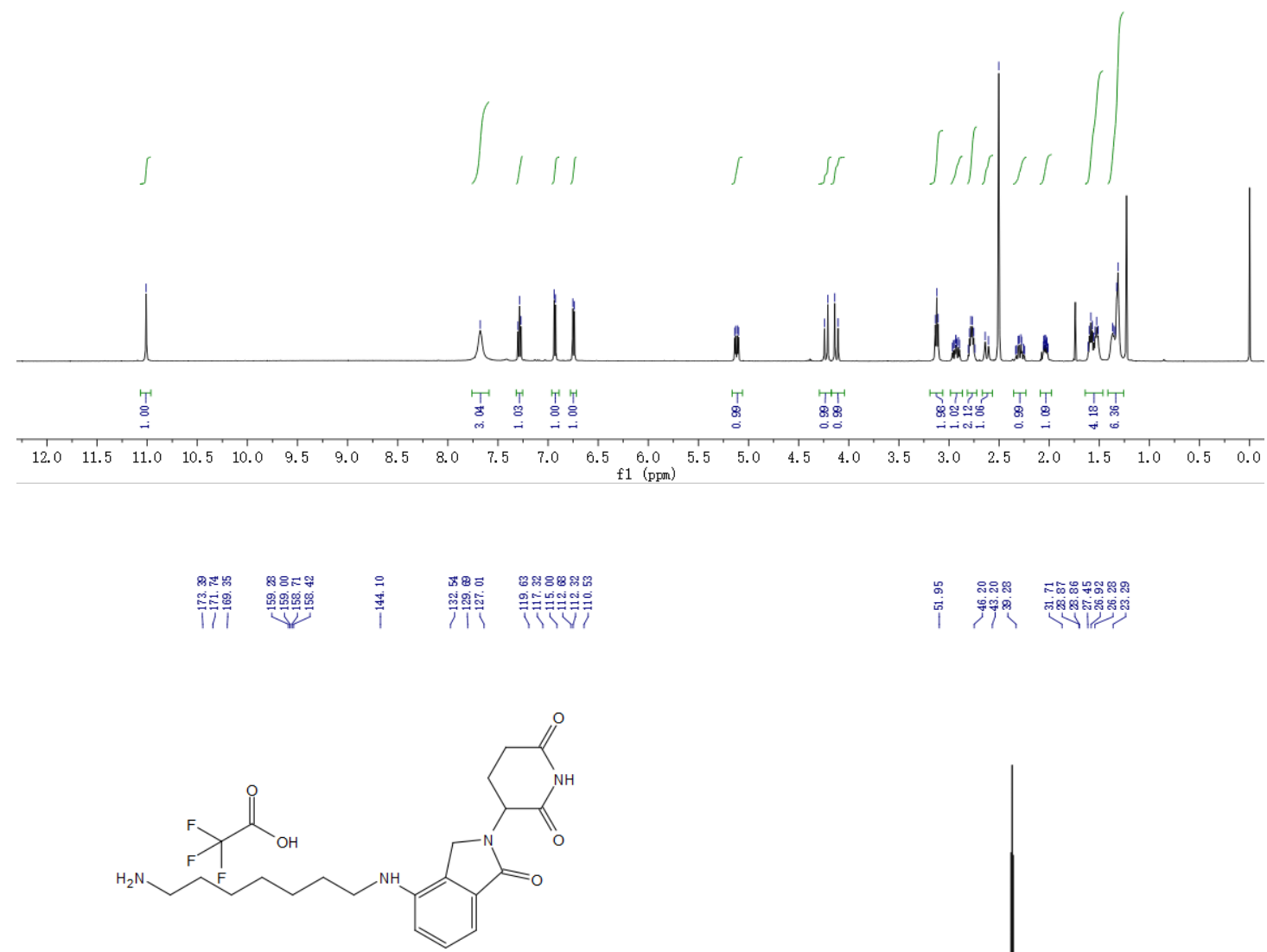

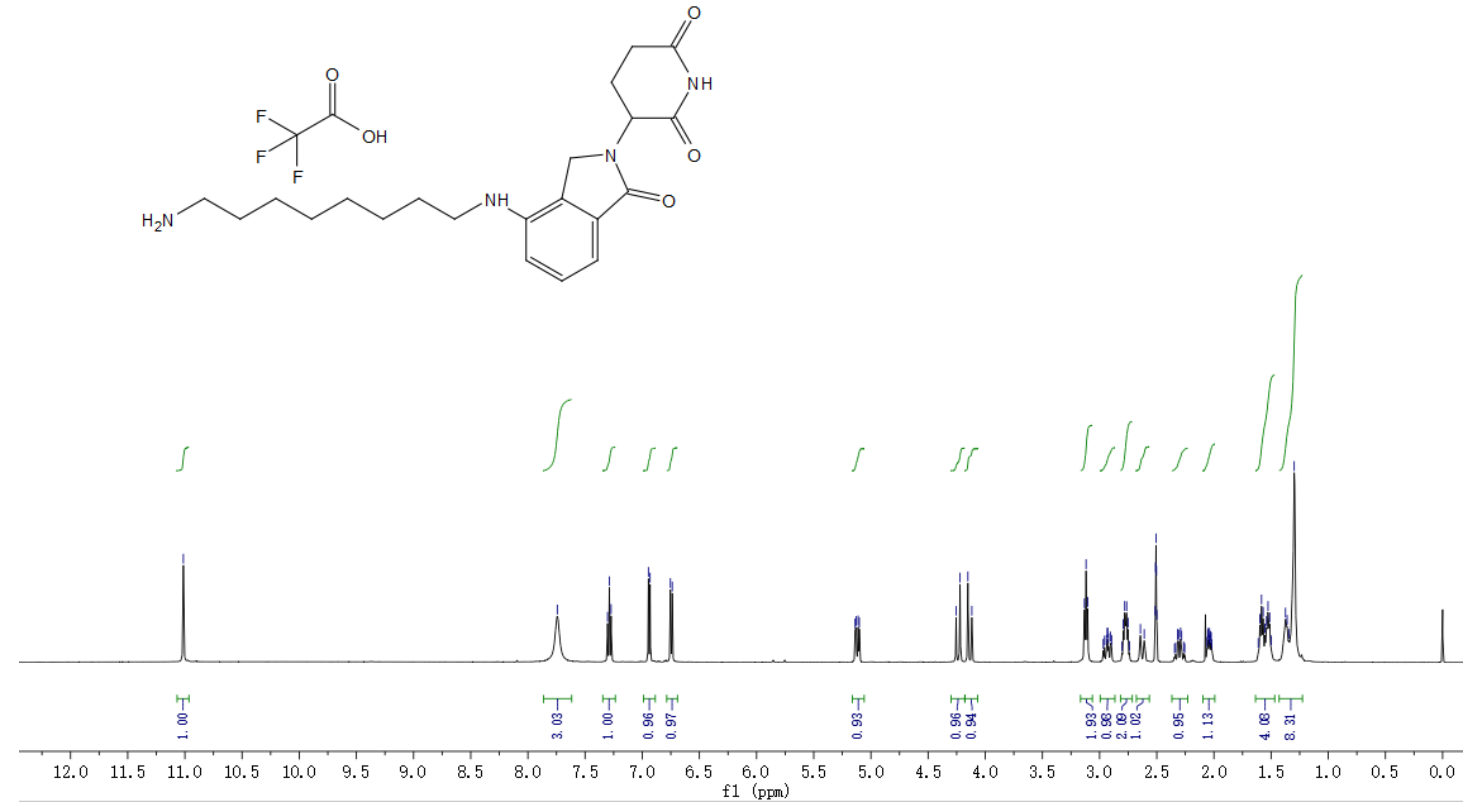

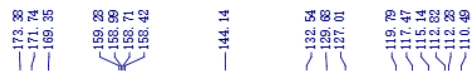

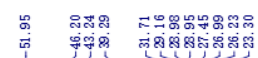

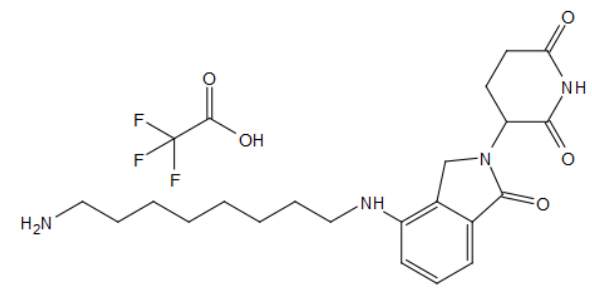

vilit

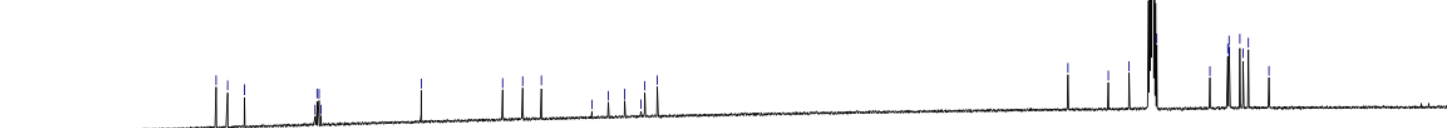

$\begin{array}{llllllllllllllllllllllllllll}1 & 190 & 180 & 170 & 160 & 150 & 140 & 130 & 120 & 110 & 100 & 90 & 80 & 70 & 60 & 50 & 40 & 30 & 20 & 10 & 0\end{array}$ 
$10 a$

$\stackrel{8}{=}$

ำ

Vivi

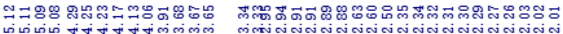

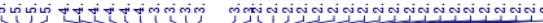<smiles>O=C(O)COCCNc1cccc2c1CN(C1CCC(=O)NC1=O)C2=O</smiles>

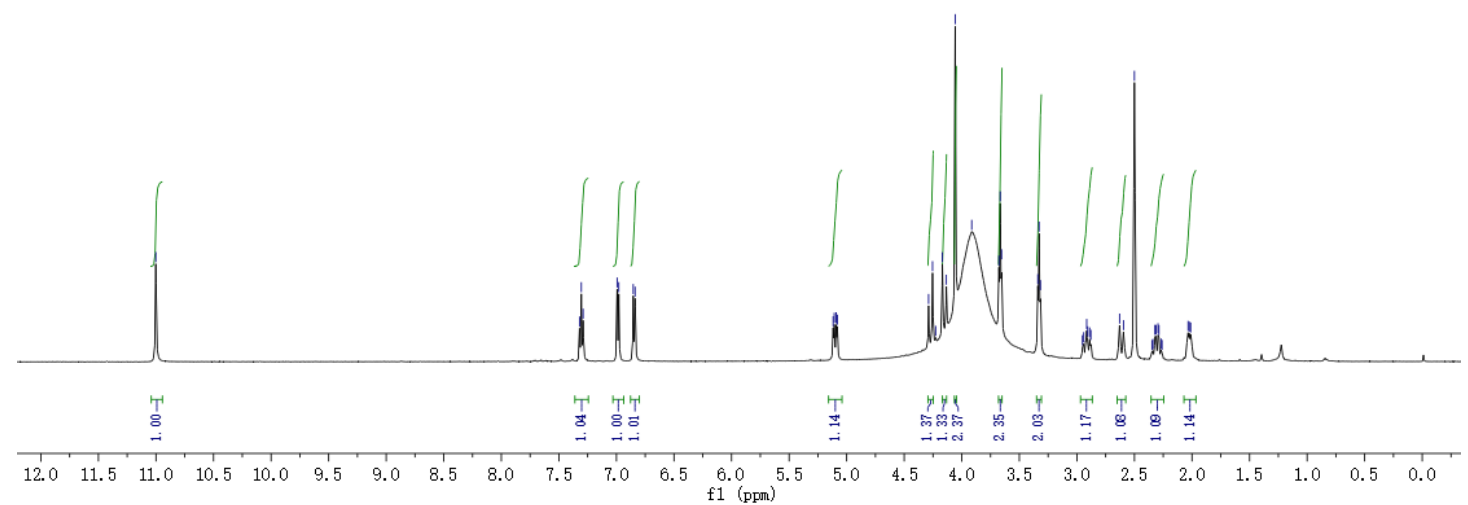

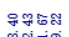

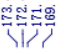

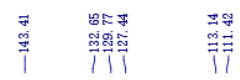

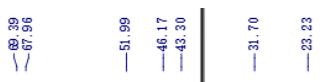

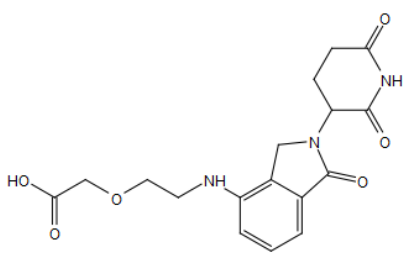

狊

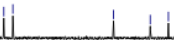

220

$200 \cdot 190 \cdot 1$

$170 \quad 160$

$40 \quad 130 \quad 120 \quad \frac{110}{110} 100$

80

60

$\begin{array}{lllll}1 & 1 & 1 & 1 & 1 \\ 40 & 30 & 20 & 10 & 0\end{array}$ 
$10 b$

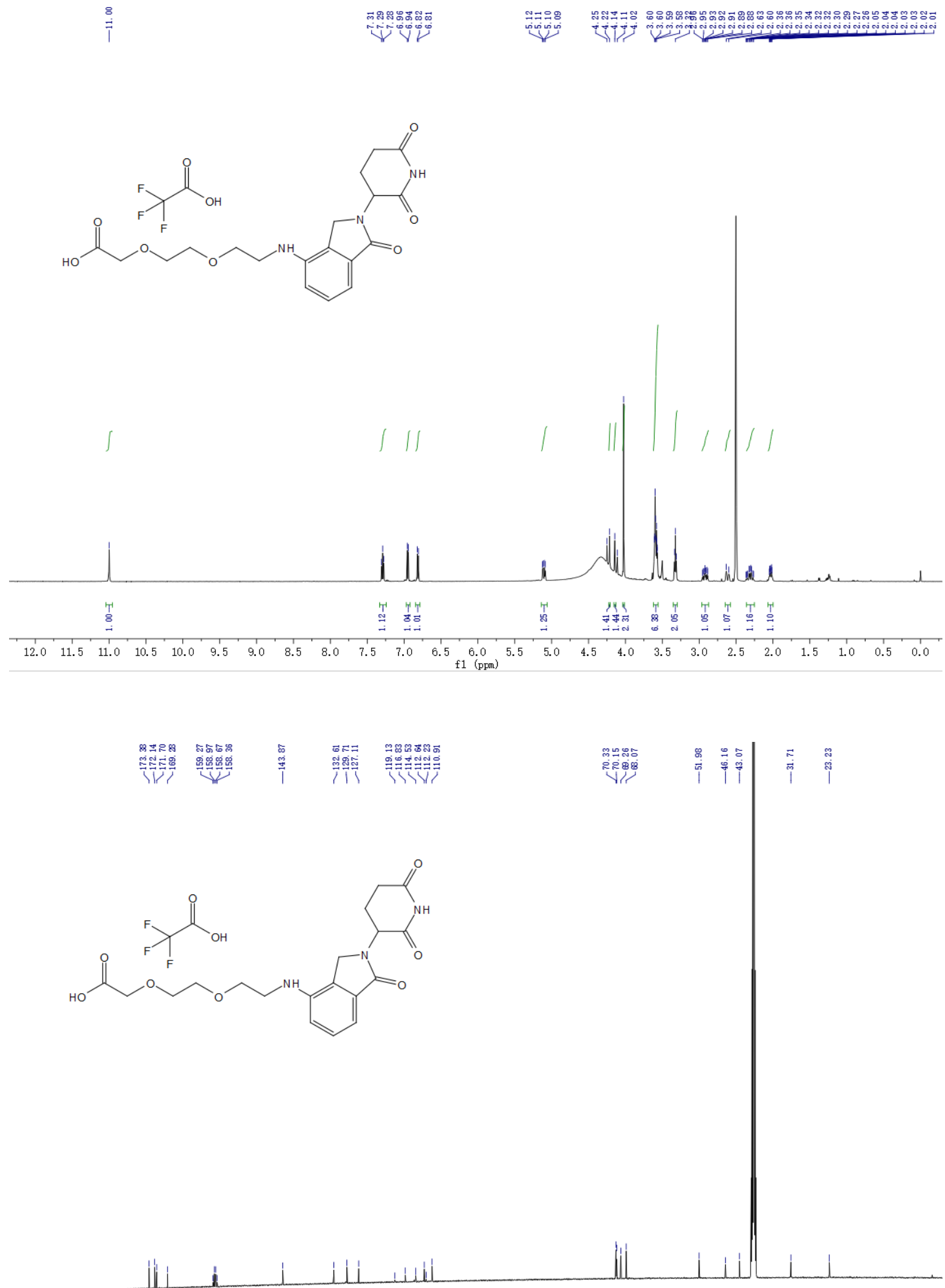

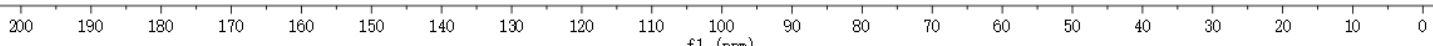


10c

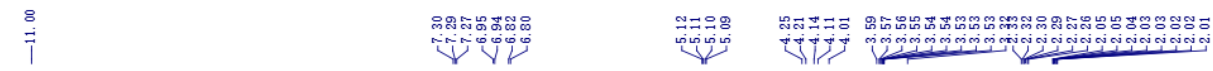<smiles>O=C(O)COCCOCCOCCNc1cccc2c1CN(C1CCC(=O)NC1=O)C2=O</smiles>

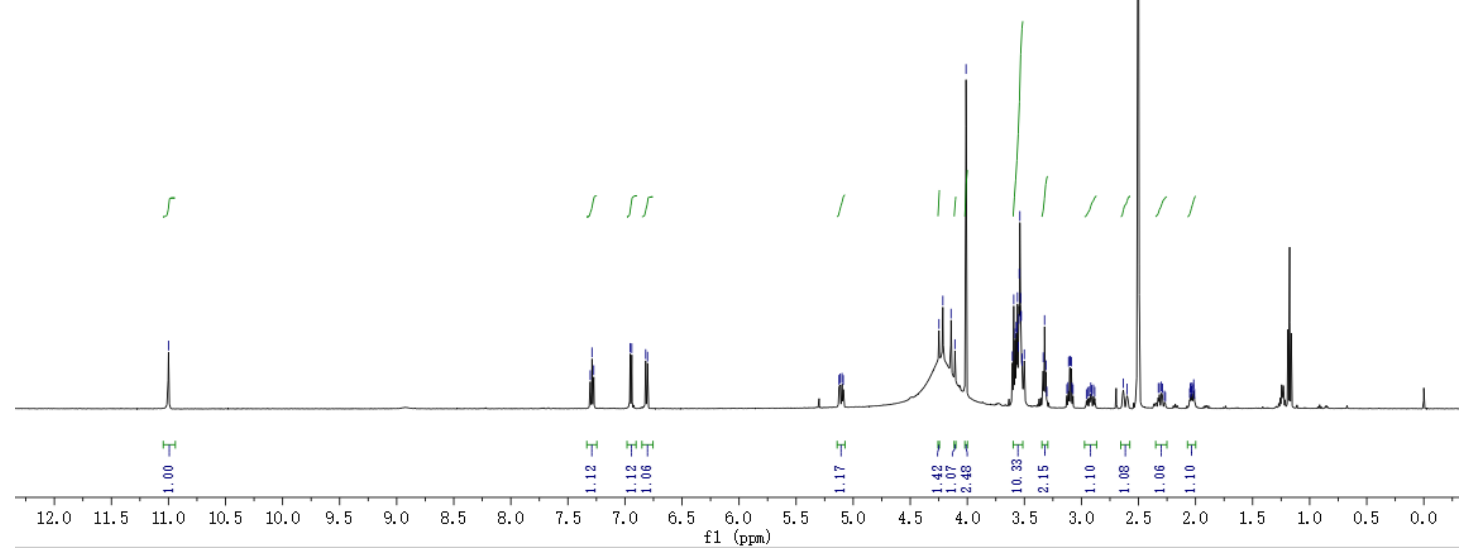

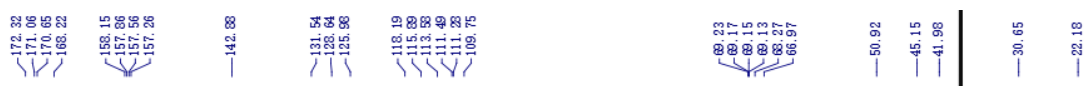<smiles>O=C(O)COCCOCCOCCNc1cccc2c1CN(C1CCC(=O)NC1=O)C2=O</smiles> 
10d

$\stackrel{8}{\vec{i}}$

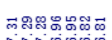

inivi

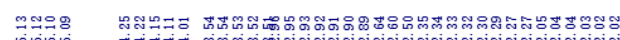

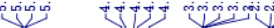<smiles>O=C(O)COCCOCCOCCOCCNc1cccc2c1CN(C1CCC(=O)NC1=O)C2=O</smiles>

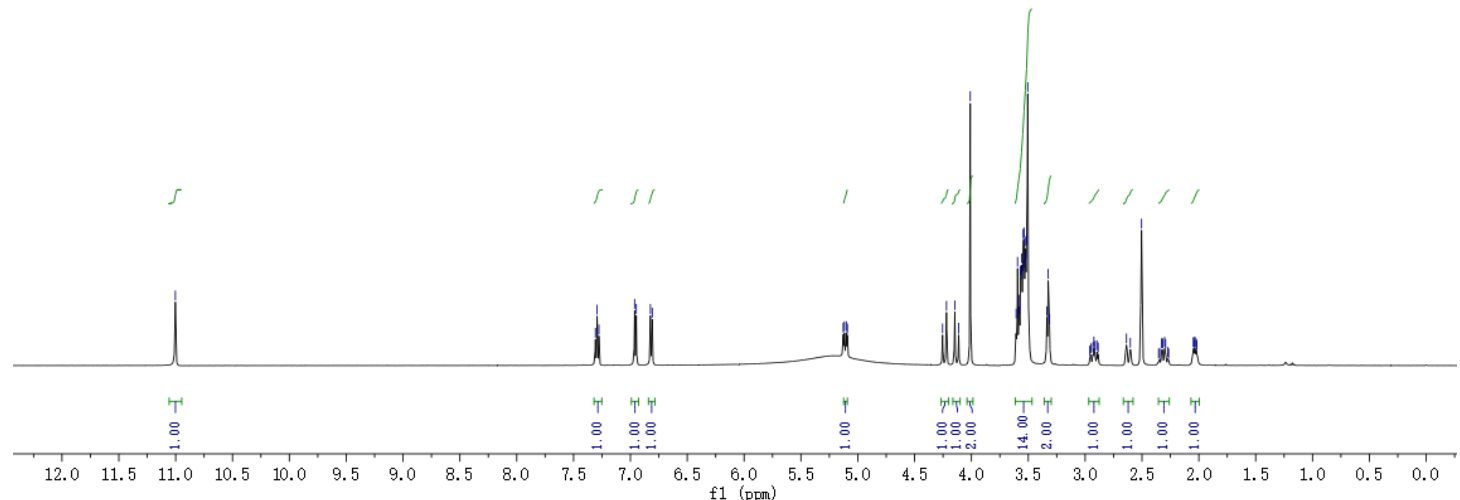

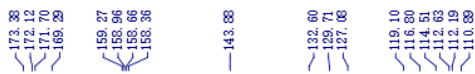

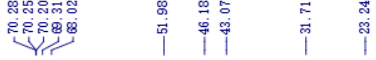<smiles>O=C(O)COCCOCCOCCOCCNc1cccc2c1CN(C1CCC(=O)NC1=O)C2=O</smiles>

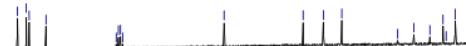

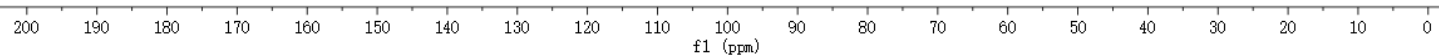


10e

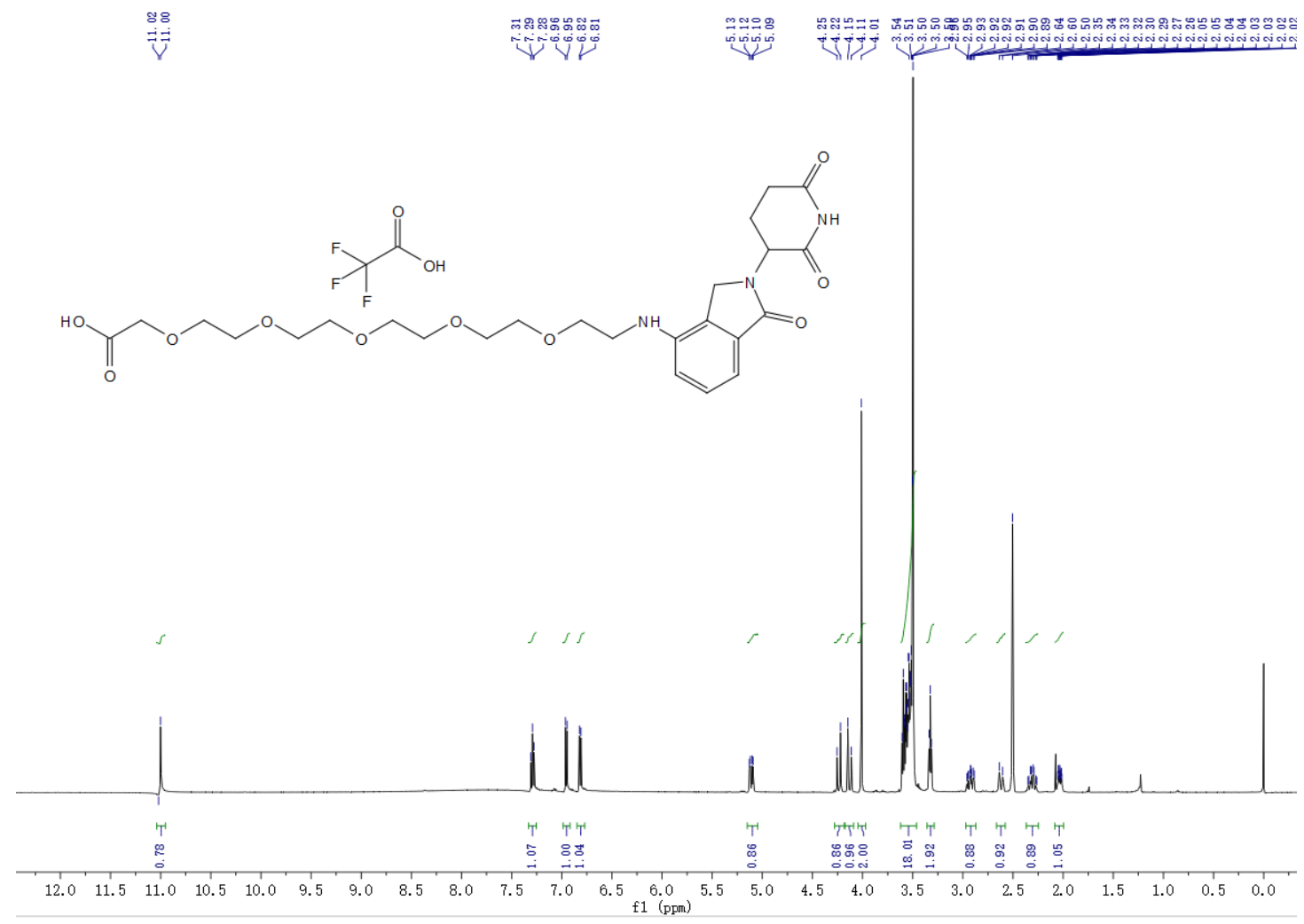

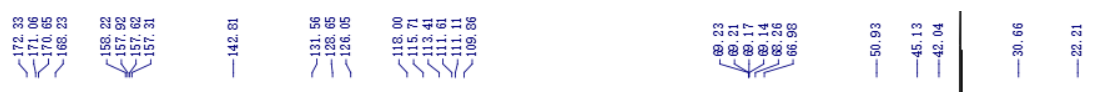

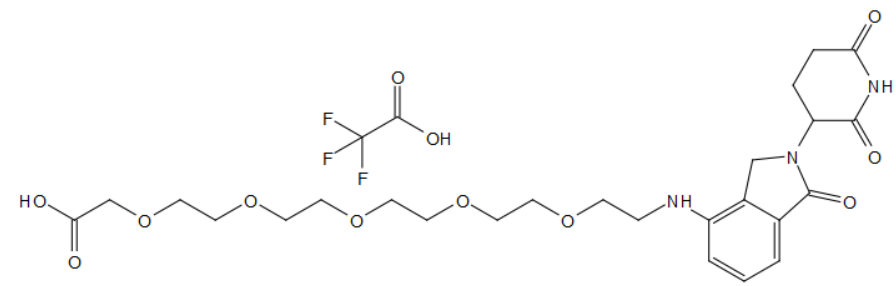

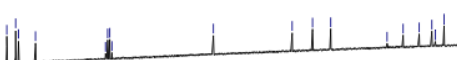

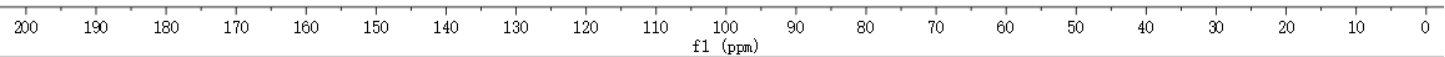


$3 a$

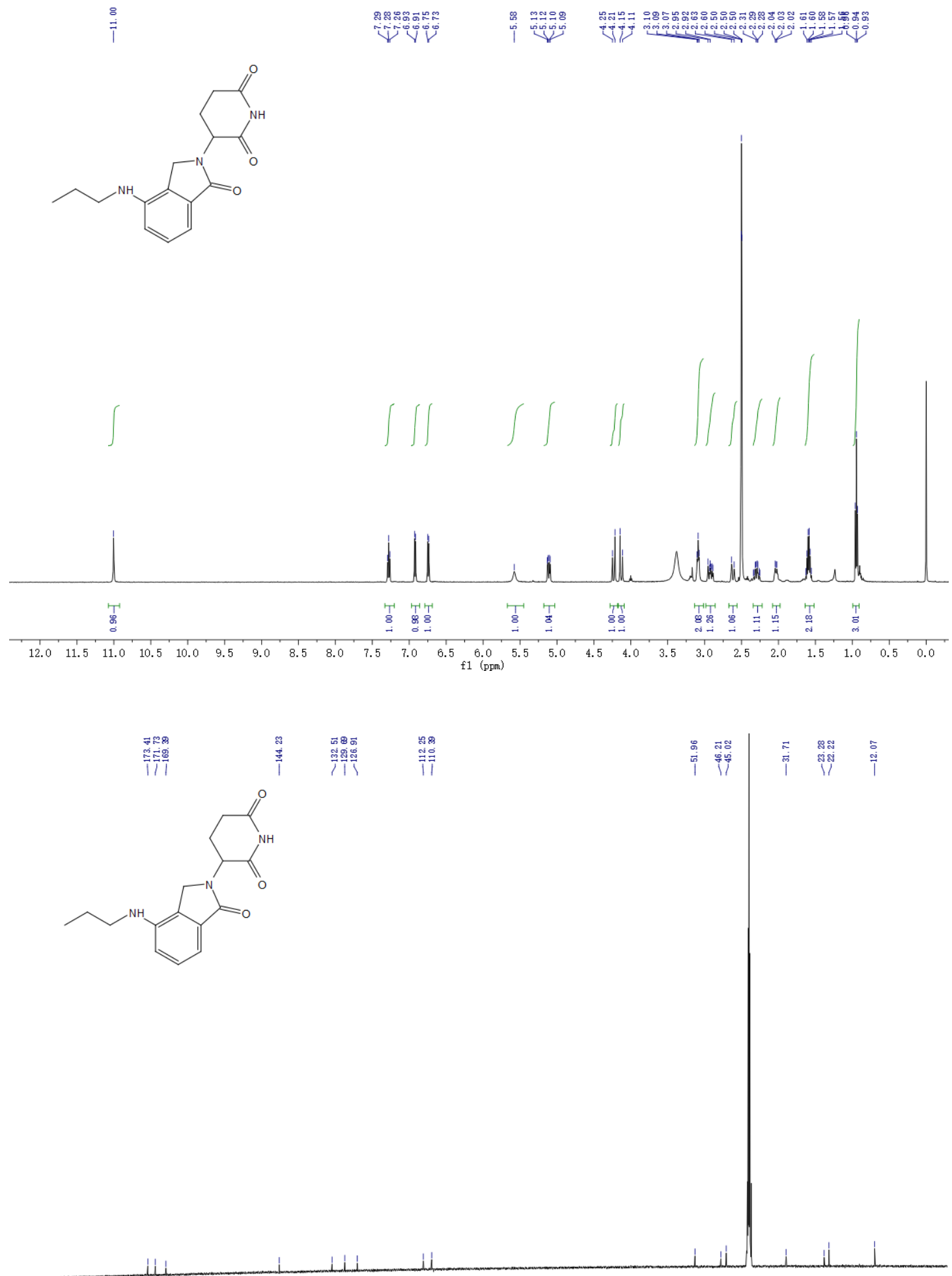

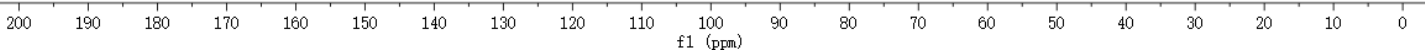


3a'

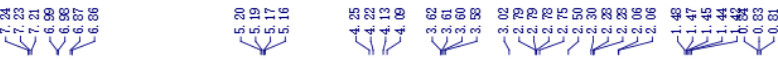
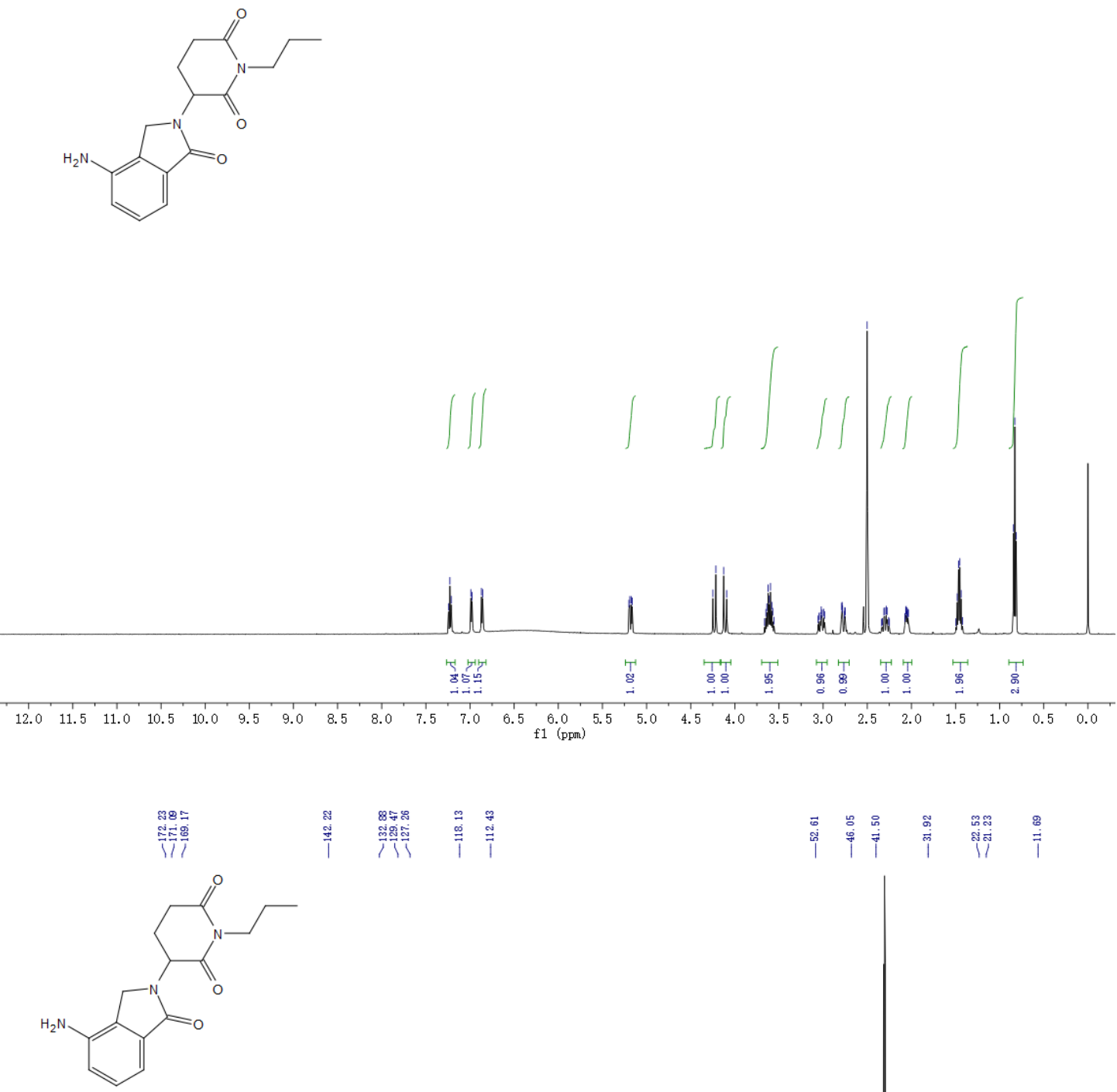

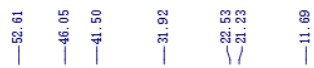


SIAIS213110

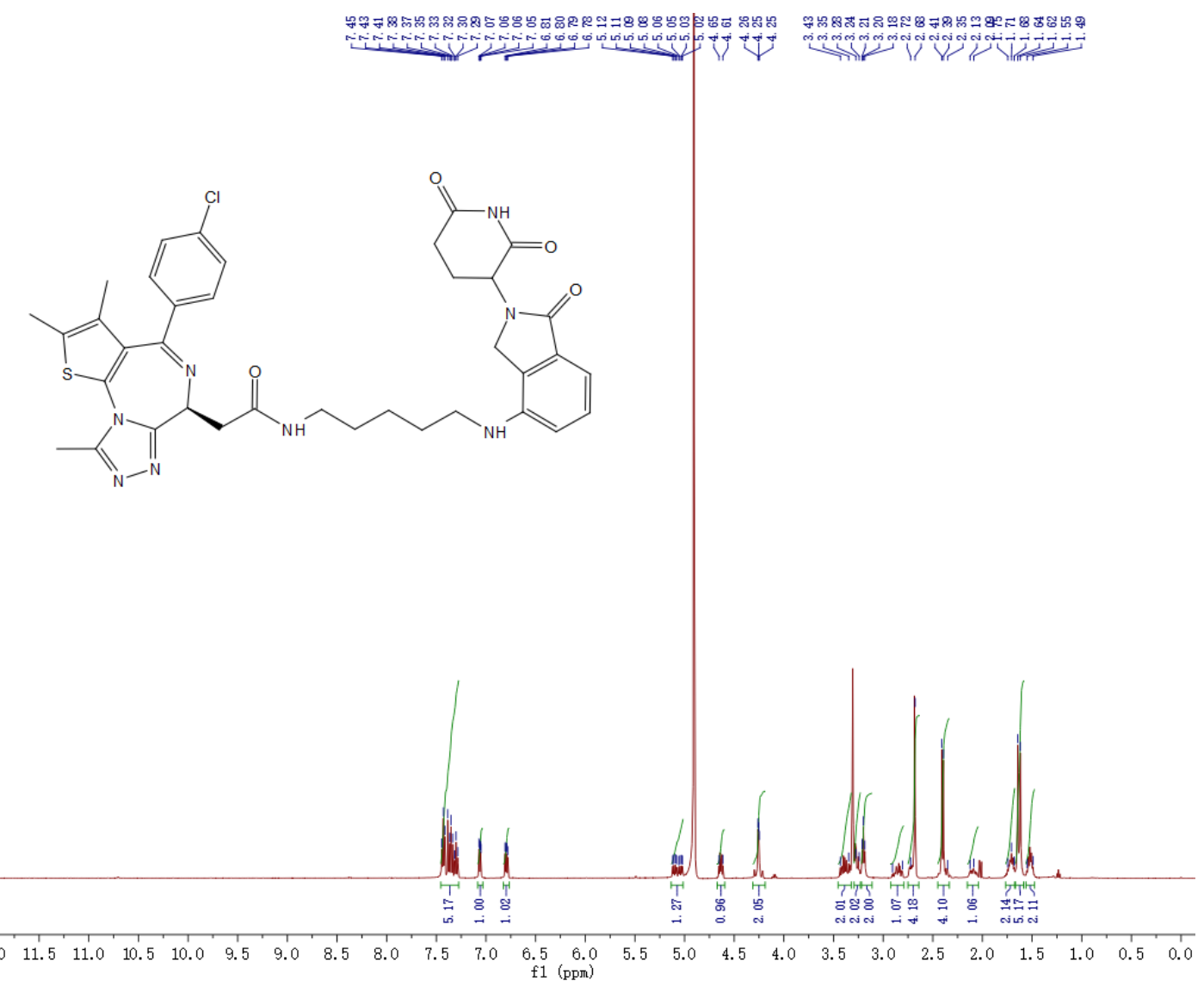

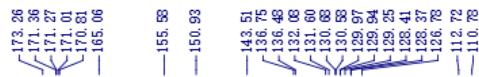

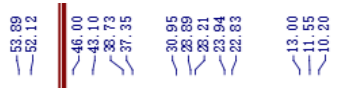
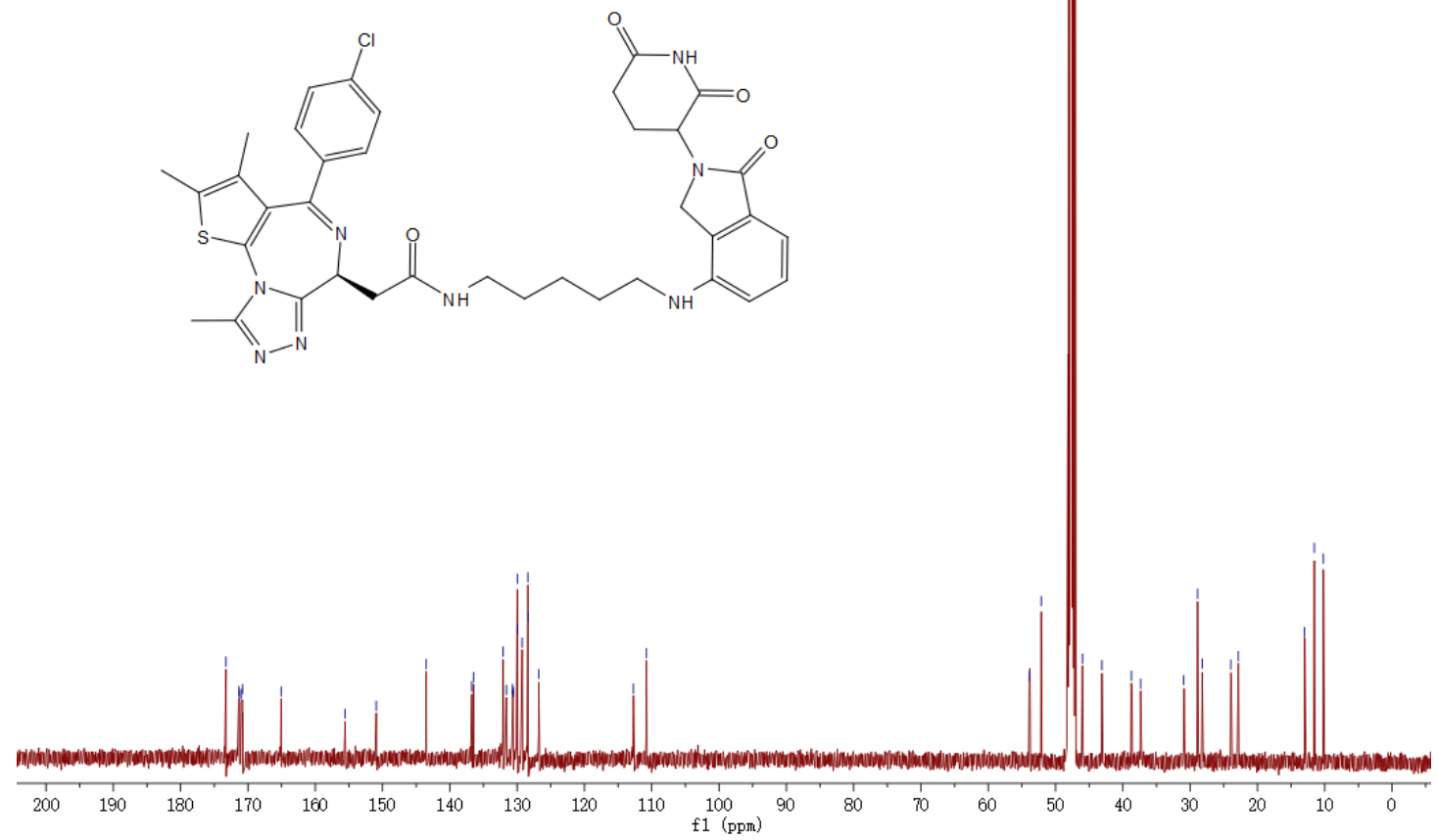